Check for updates

Cite this: RSC Adv., 2017, 7, 26037

Received 7th January 2017

Accepted 1st May 2017

DOI: $10.1039 / c 7 r a 00265 c$

rsc.li/rsc-advances

\section{Synthesis and characterisation of cerium(IV)- incorporated hydrous iron(III) oxide as an adsorbent for fluoride removal from water $\dagger$}

\author{
Kankan Mukhopadhyay, ${ }^{\mathrm{b}}$ Abir Ghosh, ${ }^{a}$ Supriyo Kumar Das, ${ }^{\mathrm{b}}$ Bibhutibhushan Show, \\ Palani Sasikumar*a and Uday Chand Ghosh (iD *a
}

Surface-altered hydrous iron(III) oxide incorporating cerium(IV) (CIHFO) was prepared and characterised via modern analytical tools for applications in fluoride removal from groundwater. The material with a Fe : $\mathrm{Ce}$ ratio of $1.0: 0.5$ ( $\mathrm{mol}: \mathrm{mol}$ ) calcined at $473 \mathrm{~K}$ shows $24.8 \pm 0.5 \mathrm{mg} \mathrm{F}^{-} \mathrm{g}^{-1}$ adsorption capacity at pH 5.0-7.0 from a solution with a concentration of $15.0 \mathrm{mg} \mathrm{L}^{-1}$; the material was established to be microcrystalline ( $\sim 5 \mathrm{~nm}$ ) with a $140.711 \mathrm{~m}^{2} \mathrm{~g}^{-1}$ surface area, irregular surface morphology and porous structure. The time-dependent fluoride adsorption capacities of CIHFO at 293, 303 and $313 \mathrm{~K}$ are well described by the pseudo-first order, pseudo-second order and Weber-Morris kinetic models, respectively. The adsorption reaction occurs via a film/boundary layer diffusion process. The very low Arrhenius activation energy $\left(E_{\mathrm{a}}=0.026 \mathrm{~kJ} \mathrm{~mol}^{-1}\right)$ indicates the high feasibility of fluoride adsorption over CIHFO. The equilibrium data fit better with the Freundlich and Redlich-Peterson $(g<1.0)$ isotherms than with the Langmuir isotherm, which suggests multilayer adsorption. The values of the Freundlich parameters, $n=3.10,4.47$ and 7.57 and $K_{F}=8.58,10.88$ and 11.25 at 293, 303 and $313 K$, respectively, indicate high affinity for fluoride. Thermodynamic analysis of the reaction equilibrium shows that the reaction is highly exothermic $\left(\Delta H^{0}=-25.924\right.$ and $-36.279 \mathrm{~kJ} \mathrm{~mol}^{-1}$ for $C_{\mathrm{i}}=25.0$ and $\left.35.0 \mathrm{mg} \mathrm{L}^{-1}\right)$, whereas the negative $\Delta G^{0}$ values indicate the spontaneous nature of the reaction. The fluoride adsorption over $\mathrm{ClHFO}$ occurs via ion-exchange that progresses to chemisorption. The presence of sulphate shows an adverse influence on fluoride adsorption by CIHFO, and the fluoride level of $2.4 \mathrm{~g}$ per $\mathrm{L}$ groundwater $(9.05 \mathrm{mg} \mathrm{F}$ $\mathrm{L}^{-1}$ ) can be reduced below the permissible value.

\section{Introduction}

The generic term 'fluorosis' is closely associated with elevated levels of fluoride concentration in drinking water. A report called 'Second thoughts about fluoride', which was published in Scientific American in 2008, demonstrated the severity of fluoride poisoning. ${ }^{1}$ Increased fluoride in groundwater is, therefore, recognised as a major threat to human health by the European Union (EU), World Health Organisation (WHO) and Environmental Protection Agency (EPA). Fluoride contamination is considered a top priority to ensure the quality of drinking water after microbial pollution. ${ }^{2}$ The beneficial and detrimental effects of fluoride to human health are highly dependent upon

${ }^{a}$ Department of Chemistry, Presidency University, 86/1 College Street, Kolkata-700073, India.E-mail: ucghosh@yahoo.co.in; sasikumar.chem@presiuniv.ac.in; Fax: +91-332241-3893; Tel: +91-33-2241-3893

${ }^{b}$ Department of Geology, Presidency University, 86/1 College Street, Kolkata-700073, India

${ }^{c}$ Department of Chemistry, Jadavpur University, Kolkata-700032, India

$\dagger$ Electronic supplementary information (ESI) available. See DOI: $10.1039 / \mathrm{c} 7 \mathrm{ra00265c}$ its concentration in drinking water and the volume of water consumed daily. The unusual bio-chemical behaviour of fluoride has necessitated restrictions on the use of groundwater for drinking without prior removal (treatment) of fluoride. At present, 32 countries worldwide report endemic levels of fluorosis. ${ }^{3}$ This problem has also been reported in India for the past few decades and is now considered a natural crisis. The supply of treated surface water to entire fluoride-prone areas is challenging, as it requires the investment of huge funds for technological shifts, manpower, operation and maintenance. Thus, it can be safely stated that access to safe drinking water is correlated with higher income levels, whereas poor rural populations are forced to consume more fluoride-contaminated water. The simplest and the cheapest way to ensure safe water is through cost-effective treatment technology. Defluoridation of excess fluoride (above $1.5 \mathrm{mg} \mathrm{\textrm {L } ^ { - 1 }}$ ) from fluoride-rich groundwater is the only pragmatic option to overcome this problem. The adsorption technique is often considered to be the most efficient and commercially viable method for fluoride removal $^{3}$ from drinking water compared to other conventional methods. The criteria to select a suitable adsorbent include adsorption capacity, cost of material, ease of operation, and the 
possibility of regeneration and reuse. Bimetallic and polymetallic nanocrystallites have drawn attention in recent decades for their efficacy in this process. Incorporation of a metal ion inside the lattice of another metal oxide results in structural modification, lattice defects, and size gradation of the metallic product. This rearrangement increases the porosity, surface area, and number of adsorption sites with oxygen and hydroxyl groups, which in turn triggers dynamic adsorption. Iron(III) oxide is one of the most effective natural water purifiers; it is abundantly available in the earth's crust. ${ }^{4}$ Hydrous iron(III) oxide, however, shows relatively low adsorption affinity for hard fluoride ions in aqueous media. ${ }^{5}$ Numerous bimetal hydrous oxides of $\mathrm{La}(\mathrm{III}), \mathrm{Ce}(\mathrm{IV}), \mathrm{Ti}(\mathrm{IV})$ and $\mathrm{Zr}$ (Iv) with $\mathrm{Fe}(\mathrm{III})$ or $\mathrm{Al}(\mathrm{III})$ have shown relatively high binding affinities with fluoride.4-18 Consequently, different researchers have prepared binary and ternary composites of metal oxides containing $\mathrm{Fe}(\mathrm{III})$ and have investigated their efficiencies in fluoride removal. ${ }^{4-6,16-31}$ As $\mathrm{Ce}(\mathrm{Iv})$ is small in size and has a high positive charge (high ionic potential), it has a strong binding affinity with fluoride. Therefore, the surface of hydrous $\mathrm{CeO}_{2}$ should have greater adsorption affinity for fluoride. Another unique feature of cerium oxide is its highly facile transformation between the +4 and +3 oxidation states. ${ }^{6}$ However, the use of hydrous $\mathrm{CeO}_{2}$ in defluoridation technology would not be cost effective for rural populations of developing countries, such as India. Thus, it would be beneficial to alter the surface of hydrous Fe(III) oxide by incorporating different proportions of $\mathrm{Ce}(\mathrm{Iv})$ oxide to upgrade the fluoride removal efficiency of pure Fe(III) oxide.

In this work, an attempt has been made to tune the synthesis of $\mathrm{Ce}($ Iv)-incorporated hydrous Fe(III) oxide (CIHFO) and apply it for fluoride adsorption from water at neutral $\mathrm{pH}$. The optimised material has been characterized by modern analysis techniques, viz. powder X-ray diffraction (XRD), X-ray fluorescence (XRF), Brunauer-Emmett-Teller (BET) analysis, atomic force microscopy (AFM), transmission electron microscopy (TEM), scanning electron microscopy (SEM), optical microscopy (OM), Fourier transform infrared (FTIR) spectroscopy, thermogravimetry analysis (TGA) and differential thermal analysis (DTA). Finally, the adsorption of fluoride on the optimised material ( $\mathrm{Fe}: \mathrm{Ce}=1.0: 0.5)$ was further investigated systematically. Thus, this article reports the synthesis, characterisation and fluoride removal efficacy of this promising newly developed material in aqueous medium.

\section{Materials and methods}

\subsection{Reagents}

The chemicals used were ceric ammonium nitrate $\left(\left(\mathrm{NH}_{4}\right)_{2}\right.$ $\left.\left[\mathrm{Ce}\left(\mathrm{NO}_{3}\right)_{6}\right]\right)$, ferric chloride $\left(\mathrm{FeCl}_{3}\right)$, sodium fluoride $(\mathrm{NaF})$, sodium hydroxide $(\mathrm{NaOH})$, hydrochloric acid $(\mathrm{HCl})$, nitric acid $\left(\mathrm{HNO}_{3}\right)$, liquid ammonia and ammonium carbonate $\left[\left(\mathrm{NH}_{4}\right)_{2} \mathrm{CO}_{3}\right]$. All chemicals and reagents used in this work were of guaranteed reagent (G.R.) grade (Merck India, Mumbai).

\subsection{Fluoride solution}

A standard stock solution of fluoride $\left(1000 \mathrm{mg} \mathrm{L^{-1 }}\right)$ was prepared by dissolving an appropriate amount $(2.21 \mathrm{~g})$ of sodium fluoride in one litre of de-ionised water. The required concentrations of fluoride solution were achieved by appropriate dilution of the stock solution with fluoride-free double de-ionized water.

\subsection{Fluoride analysis}

The fluoride samples were analysed using an ion-selective electrode (Hach, USA). Here, $25 \mathrm{~mL}$ of filtrate was placed in a polythene (PE) beaker, and fluoride adjustment buffer powder (Hach) was dissolved to adjust the from $\mathrm{pH} 5.0$ to 7.8. The calibrated ion-selective electrode was then dipped in a sample solution to determine the fluoride concentration.

\subsection{Ce(Iv)-incorporated hydrous Fe(III) oxide (CIHFO) preparation}

The method of preparation of hydrous cerium(Iv)-incorporated iron(III) oxide adopted here is different from previously described methods. ${ }^{6,18}$ Here, a batch of cerium incorporated hydrous Fe(III) oxide was synthesised by co-precipitation in an ambient laboratory environment. The concentration of ferric chloride $(0.1 \mathrm{M})$ solution in $0.1 \mathrm{M} \mathrm{HCl}$ was kept constant, while the concentration of ammonium ceric nitrate in $0.1 \mathrm{M} \mathrm{HNO}_{3}$ was varied. Both solutions were mixed together, and the $\mathrm{pH}$ of the mixture was increased to $\sim 6.0$ to 7.0 by dropwise addition of ammonia solution (mixture of $25 \%$ ammonia solution and 0.1 M ammonium carbonate solution). The brownish-yellow gel-like precipitate was developed and was aged for 24 hours. The precipitate was filtered through a $0.45 \mu \mathrm{m}$ membrane filter and repetitively washed with deionised water to remove extraneous contaminants. The residue was dried at $75{ }^{\circ} \mathrm{C}\left( \pm 5{ }^{\circ} \mathrm{C}\right)$ in an air oven. The hot mass immediately after drying was treated with cold water in order to break it into small particles. The airdried particles were ground and sieved to collect the particles with sizes between 50 and 100 mesh (particle size: 140 to 290 $\mu \mathrm{m})$, which were used to conduct the experiments.

\subsection{Instruments}

Powder X-ray diffraction (XRD), X-ray fluorescence (XRF), optical microscopy (OM), scanning electron microscopy (SEM), transmission electron microscopy (TEM), atomic force microscopy (AFM), Brunauer-Emmett-Teller (BET) nitrogen (vapour) adsorption-desorption and Föurier transform infrared (FTIR) spectroscopy were used to characterize the materials. The powder XRD patterns of the materials were recorded using an Xray diffractometer (Bruker D8 Advance) equipped with $\mathrm{Cu}-\mathrm{K} \alpha$ radiation $\left(\lambda=1.5418 \AA\right.$ ) at a scanning speed of $0.4^{\circ} \mathrm{min}^{-1}$ between $2 \theta=10^{\circ}$ and $70^{\circ}$, operated at a $40 \mathrm{kV}$ voltage and an applied potential current of $30 \mathrm{~mA}$. Transmission electron microscopic (TECNAI G ${ }^{2} 30 \mathrm{ST}$, FEI, Netherlands) images were recorded at different magnifications. The samples for TEM were suspended in $0.25 \%$ vinylec-E chloroform solution by sonication, and one drop of the suspension was casted onto a carbon film-coated copper grid and dried under an IR lamp. The grid was then mounted on a Double Tilt Specimen Holder to perform the TEM analysis. X-ray fluorescence (XRF-Panalytical Axios) of the optimised material was analysed by accurately 
weighing $8.0 \mathrm{~g}$ of sample ( $\sim 200$ mesh), which was thoroughly mixed with $1.0 \mathrm{~g}$ of wax. This mixture was packed in an aluminium cup $40 \mathrm{~mm}$ in diameter and pressed at $200 \mathrm{KN}$. This was exposed to X-rays for analysis. Atomic force microscopic (AFM) images were taken with an Innova Atomic Force Microscope (Bruker AXS Pte Ltd) using optical beam deflection to monitor the displacement of a micro-fabricated silicon cantilever with a spring constant of $80 \mathrm{Nm}^{-1}$ to visualize the topography of the mixed oxide surface. OM images were recorded using a Nikon Eclipse LV100 POL microscope. TG and DT were measured using a Perkin Elmer system; the variations in weight and heat energy during the phase transitions of the materials were measured in a variety of gaseous environments in the temperature range of $50{ }^{\circ} \mathrm{C}$ to $1200{ }^{\circ} \mathrm{C}$. The surface areas of the materials were analyzed by the Brunauer-Emmett-Teller (BET) method by $\mathrm{N}_{2 \text { (vapour) }}$ adsorption at $77 \mathrm{~K}$ using a high-speed surface analyzer (Quantachrome Nova4000e). The adsorption of $\mathrm{N}_{2 \text { (vapour) }}$ at a temperature of $77 \mathrm{~K}$ results in an adsorption isotherm commonly referred to as the Brunauer-Emmett-Teller (BET) isotherm. Multiplying the number of gas molecules required to cover an adsorbent surface with a monolayer of adsorbed molecules with the cross-sectional area of an adsorbate material gives the approximate sample surface area. The $\mathrm{pH}_{\mathrm{PZC}}$ values of the samples were analysed by the $\mathrm{pH}$ metric method used by Babic et al. ${ }^{32}$

\subsection{Experimental design}

Batch adsorption is a systematic static process to evaluate the removal efficacy of an adsorbent. Here, a measured volume of fluoride solution $(100 \mathrm{~mL})$ with a desired initial concentration $\left(C_{\mathrm{i}}, \mathrm{mg} \mathrm{\textrm {L } ^ { - 1 }}\right)$ was placed in a $250 \mathrm{~mL} \mathrm{PE}$ bottle along with a definite mass $(0.050 \mathrm{~g})$ of CIHFO (except for the dose variation experiments) and agitated at $250( \pm 5) \mathrm{rpm}$ inside a thermostatic shaker for 2 hours (except for the time-dependent experiments). The solid mass was immediately separated by filtration, and the filtrate was analysed to determine the residual concentration of fluoride $\left(C_{\mathrm{f}}, \mathrm{mg} \mathrm{L}^{-1}\right)$. As the material was prepared with the aim of treating groundwater, the batch experimental program was conducted in the neutral $\mathrm{pH}$ range, except for the $\mathrm{pH}$ influence experiments.

The composition of CIHFO was optimised by preparing samples with varying mole proportions of Ce in Fe. To optimise the drying temperature, the optimized CIHFO samples were separately dried for five hours at $100{ }^{\circ} \mathrm{C}(373 \mathrm{~K})$ to $600{ }^{\circ} \mathrm{C}(873 \mathrm{~K})$ with increments of $100^{\circ} \mathrm{C}$; these samples were employed for the adsorption experiments described above.

The effects of the solution $\mathrm{pH}$ on fluoride adsorption were investigated independently at pre-programmed $\mathrm{pH}_{\mathrm{i}}$ values from 3.0 to 10.0 by unit increments, employing two different fluoride solutions $\left(C_{\mathrm{i}}: 10.0\right.$ and $\left.15.0 \mathrm{mg} \mathrm{L}^{-1}\right)$. The $\mathrm{pH}$ value of each test solution was adjusted with $0.1 \mathrm{M} \mathrm{HCl}$ or $0.1 \mathrm{M} \mathrm{NaOH}$ solution.

Time-dependent fluoride adsorption experiments with CIHFO (reaction kinetics) were conducted with three separate concentrations of fluoride solution. The same experiment was also carried out at three different temperatures $(293 \mathrm{~K}, 303 \mathrm{~K}$ and $313 \mathrm{~K}$ ) with a fixed fluoride concentration $\left(15.0 \mathrm{mg} \mathrm{L}^{-1}\right)$.
Equilibrium experiments were carried out using fluoride solutions with $C_{\mathrm{i}}$ values ranging from 10.0 to $60.0 \mathrm{mg} \mathrm{L}^{-1}$. The scheduled experiments were conducted separately at $293 \mathrm{~K}, 303$ $\mathrm{K}$, and $313 \mathrm{~K}$ at a solution $\mathrm{pH}_{\mathrm{i}}$ of 7.0 , an agitation time of 2 hours and a speed of $250 \pm 5 \mathrm{rpm}$. The fluoride concentration remaining at equilibrium $\left(C_{\mathrm{e}}, \mathrm{mg} \mathrm{\textrm {L } ^ { - 1 }}\right)$ was determined by the ion-selective electrode, and the equilibrium capacity $\left(Q_{\mathrm{e}}, \mathrm{mg}\right.$ $\left.\mathrm{g}^{-1}\right)$ was calculated. The thermodynamic parameters $\left(\Delta S^{0}, \Delta H^{0}\right.$, $\Delta G^{0}$ ) were evaluated from the results of the equilibrium analysis.

The adsorption of fluoride over tuned CIHFO may be adversely influenced by the presence of ions occurring in groundwater, such as $\mathrm{Ca}^{2+}, \mathrm{Mg}^{2+}, \mathrm{HPO}_{4}{ }^{2-}, \mathrm{SO}_{4}{ }^{2-}, \mathrm{HCO}_{3}{ }^{-}, \mathrm{NO}_{3}{ }^{-}$ and $\mathrm{Cl}^{-}$. To evaluate this interference, batch absorber experiments were conducted at $\mathrm{pH} \sim 7.0$ as described above using the fluoride solution with $C_{\mathrm{i}}=10.0 \mathrm{mg} \mathrm{\textrm {L } ^ { - 1 }}$ in the presence of different concentrations of competing ions.

For the desorption experiments, $0.05 \mathrm{~g}$ of fluoride-enriched CIHFO (16.4 mg F $\mathrm{g}^{-1}$ ) was agitated at $250( \pm 5) \mathrm{rpm}$ for one hour along with $50 \mathrm{~mL}$ of $\mathrm{NaOH}$ solution with various concentrations in the range from 0.1 to $4.0 \mathrm{M}$.

\subsection{Adsorption capacity}

Immediately after each experiment, the adsorbent particles were filtered through a $0.45 \mu \mathrm{m}$ membrane filter. The residual fluoride level in each filtrate was analysed. The amount of fluoride adsorbed by CIHFO was calculated using the following mass balance equation (eqn (1)):

$$
Q_{\mathrm{e}}=\left(C_{\mathrm{i}}-C_{\mathrm{f}}\right) \times V / M
$$

where $Q_{\mathrm{e}}$ is the adsorption capacity $\left(\mathrm{mg} \mathrm{g}^{-1}\right), V$ is the volume of the solution (L), and $M$ is the mass of the adsorbent (g) used to carry out the batch experiments. $C_{\mathrm{i}}$ and $C_{\mathrm{f}}$ were defined previously.

\subsection{Field validation}

To establish the applicability of CIHFO in groundwater treatment, validation of the removal efficacy of the optimised material with field water is an essential step. To achieve this goal, water samples were collected in thoroughly cleaned PE bottles from different hand pump-attached tube wells in the Kashipur block, the most adversely fluoride-affected region of Purulia district, West Bengal, India. The fluoride concentrations of the collected water samples were analysed in the laboratory by the ion selective electrode, and the water samples with maximum fluoride concentrations (Kharai village) were used for the field validation.

\section{Results and discussion}

\subsection{Influence of cerium content in CIHFO on fluoride adsorption}

Fig. 1A shows the changes in the fluoride adsorption capacity with changing mole ratio of $\mathrm{Fe}(\mathrm{III})$ to $\mathrm{Ce}(\mathrm{Iv})$ in CIHFO from $1.0: 0.0$ to $0.0: 1.0$; the results showed an increase of the 
fluoride adsorption amount with increasing cerium content from $1.0: 0.0$ to $1.0: 0.5$, followed by a decrease until the Fe : Ce mole proportion reached $1: 1$. Similar observations have been reported by others., ${ }^{710}$ Although the fluoride adsorption was highest for the pure ceria material $\left(25.3 \mathrm{mg} \mathrm{g}^{-1}\right)$, the fluoride adsorption amount was appreciably high compared to pure iron oxide at a Fe to Ce ratio of $1.0: 0.5$. This may be beneficial in light of the cost of the material.

Fig. 1B shows that the adsorption amount/gram of calcined CIHFO decreased with increasing calcination temperature at and above $300{ }^{\circ} \mathrm{C}(573 \mathrm{~K})$. The adsorbent calcined at $200{ }^{\circ} \mathrm{C}(473$ $\mathrm{K})$ showed the maximum fluoride adsorption amount $(24.8 \mathrm{mg}$ $\left.\mathrm{g}^{-1}\right)$ from an aqueous solution of fluoride $\left(C_{\mathrm{i}}=15.0 \mathrm{mg} \mathrm{L}^{-1}\right)$. As the adsorbent material was prepared by a co-precipitation method, the as-prepared CIHFO contains hydrous oxides of iron and cerium; the hydroxyl groups on these metal oxide surfaces are the primary adsorption sites for fluoride adsorption. At the temperature of $473 \mathrm{~K}$, the surface water molecules attached by hydrogen bonding are removed, and the surface hydroxyl groups become available to the solute for adsorption reactions, resulting in a higher adsorption value. These hydroxyl groups were deliberately eliminated from the surfaces of the metal oxides by increasing the calcination temperature $(>473 \mathrm{~K})$, which is similar to other reports. ${ }^{\mathbf{8 1 0 , 1 6}}$ As a result, the adsorption capacity of the proposed adsorbent decreased sharply.

\subsection{Characterisation of CIHFO}

The CIHFO material with a $\mathrm{Fe}: \mathrm{Ce}$ mole ratio of $1.0: 0.5$ calcined at $200{ }^{\circ} \mathrm{C}(473 \mathrm{~K})$ showed the highest affinity for fluoride; it was characterised by powder XRD, TEM, OM, SEM-EDX, XRF for composition, FTIR, TG and DT analyses. The powder XRD pattern (Fig. $\mathrm{S}_{1} \mathrm{~A} \dagger$ ) of the CIHFO (Fe : $\left.\mathrm{Ce}=1.0: 0.5\right)$ sample shows the presence of microcrystalline particles and crystallites $\sim 5 \mathrm{~nm}$ in size. Comparison of the $2 \theta\left(^{\circ}\right)$ values for the XRD peak positions of the newly synthesized material CIHFO with literature reports ${ }^{18}$ of $\mathrm{Fe}_{2} \mathrm{O}_{3}$ and $\mathrm{CeO}_{2}\left[23.03^{\circ}, 28.91^{\circ}, 32.78^{\circ}, 48.29^{\circ}\right.$, $57.11^{\circ}$ for CIHFO; $24.21^{\circ}\left(\begin{array}{lll}0 & 1 & 2\end{array}\right), 33.25^{\circ}\left(\begin{array}{lll}1 & 0 & 4\end{array}\right), 35.72^{\circ}\left(\begin{array}{lll}1 & 1 & 0\end{array}\right)$,

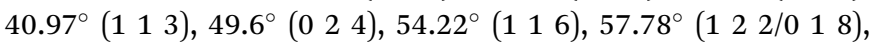

$62.61^{\circ}(214), 64.17^{\circ}\left(\begin{array}{lll}3 & 0 & 0\end{array}\right), 72.18^{\circ}$ (1 1 9), $75.67^{\circ}$ (2 20 ) for $\mathrm{Fe}_{2} \mathrm{O}_{3}$ and $33.0^{\circ}\left(\begin{array}{lll}2 & 0 & 0\end{array}\right), 56.3^{\circ}(311), 69.43^{\circ}$ (4 000$), 76.69^{\circ}$ (3 31 1), $79.04^{\circ}$ ( $\left.\begin{array}{lll}4 & 2 & 0\end{array}\right)$ for $\mathrm{CeO}_{2}$ ] showed that two peaks of CIHFO very closely matched those of $\mathrm{CeO}_{2}$ phase with cubic structures corresponding to ( $h k l)$ values of $\left(\begin{array}{lll}1 & 1 & 1\end{array}\right)$ and $\left(\begin{array}{lll}2 & 2 & 0\end{array}\right)$, while one peak was common to $\mathrm{Ce}_{2} \mathrm{O}_{3}$ phase with a hexagonal structure corresponding to the $(h k l)$ value $\left(\begin{array}{lll}2 & 0 & 1\end{array}\right)$. However, only one XRD peak of CIHFO was found to be close to $\alpha-\mathrm{Fe}_{2} \mathrm{O}_{3}$; this clearly indicates the incorporation of $\mathrm{Fe}^{3+}$ ion into the crystal structure of $\mathrm{CeO}_{2}$. Furthermore, XRF analysis to determine the composition of the sample quantified the presence of $55.082 \% \mathrm{Fe}_{2} \mathrm{O}_{3}$ and $33.626 \%$ $\mathrm{CeO}_{2}$ with some other minor constituents as impurities, namely $\mathrm{Al}_{2} \mathrm{O}_{3}$ (0.059\%), $\mathrm{SiO}_{2}$ (0.456\%), $\mathrm{CaO}$ (0.014\%), $\mathrm{MnO}$ (0.395\%), and $\mathrm{Cl}^{-}(6.97 \%)$. The established empirical formula of the hybrid oxide is $\mathrm{Fe}_{3.72} \mathrm{CeO}_{7.59}$. Fig. 2A-C shows TEM images at low and high resolution, respectively. Fig. 2A shows the presence of agglomerated particles, and B shows particles $5 \mathrm{~nm}$ in size which are microcrystalline in nature. The fingerprint-like appearance in the high resolution TEM image in Fig. 2C indicates the presence of internal crystallinity in the particles. The presence of the associated crystallite particles was also prominently observed in the optical microscopic images (Fig. 2D and E). The SEM images (Fig. 2F and G) show the irregular surface morphology of the material. The SEM-EDX spectrum (Fig. 2H) also supports the presence of higher iron content than cerium, in contrast to a material reported ${ }^{6}$ by another research group. This is in agreement with our intention when preparing the material. From the analytical data, the empirical formula of the hybrid oxide is established as $\mathrm{Fe}_{3.72} \mathrm{CeO}_{7.59}$.

The FTIR spectra of iron(III) oxide, cerium(Iv) oxide and composition-optimised CIHFO are compared in Fig. 3A. It can be seen that the stretching and bending modes of the vibrations for $\mathrm{O}-\mathrm{H}$ bonds are indicated by the bands at wave numbers of (v) 3000 to $3500 \mathrm{~cm}^{-1}$ and $\sim 1630 \mathrm{~cm}^{-1}$, respectively. ${ }^{10,13}$ In addition, the bands recorded in the spectra at $\nu=1300$ to 1400 $\mathrm{cm}^{-1}$ are the stretching modes of $\mathrm{M}-\mathrm{O}$ bonds and those around $750 \mathrm{~cm}^{-1}$ are the bending modes of $\mathrm{M}-\mathrm{O}$ bonds. ${ }^{31}$ The FTIR spectrum for HFO (black) showed bands for Fe-O at $\nu=1318$ $\mathrm{cm}^{-1}$ and for HCO at $\nu=1396 \mathrm{~cm}^{-1}$, while that for CIHFO (red)
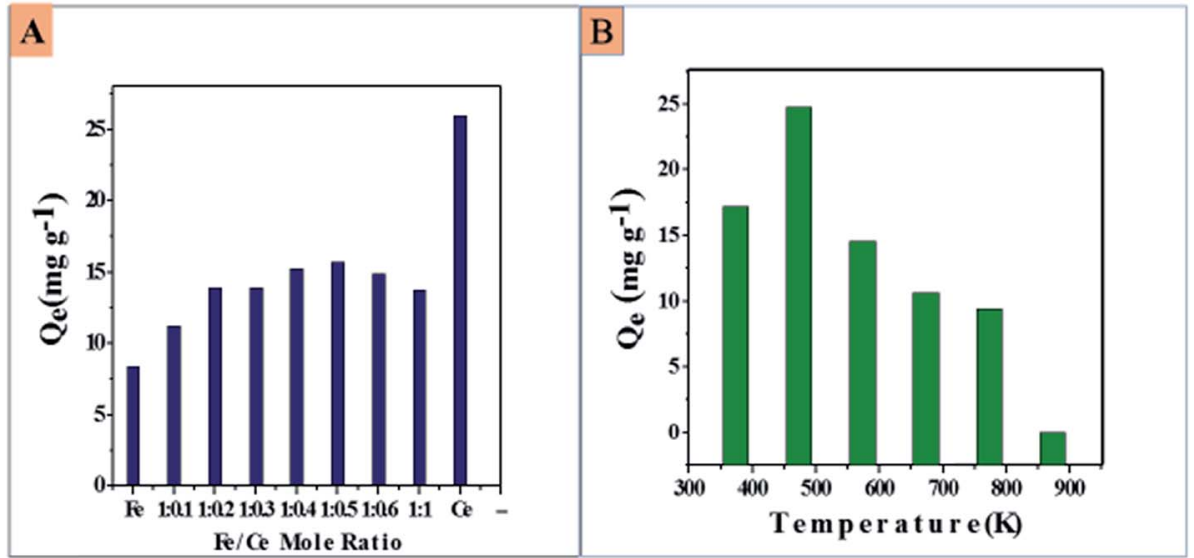

Fig. 1 Effects of variations of the (A) Fe/Ce mole ratio and (B) calcined temperature of the Fe : Ce $(1.0: 0.5)$ material on the fluoride adsorption capacity of ClHFO. Adsorbent dose: $0.05 \mathrm{~g}$ per $100 \mathrm{~mL}$ of fluoride solution, concentration: $15.0 \mathrm{mg} \mathrm{L}{ }^{-1}, \mathrm{pH}: 7.0$ ( \pm 0.2$)$, agitation time: $60 \mathrm{~min}$. 

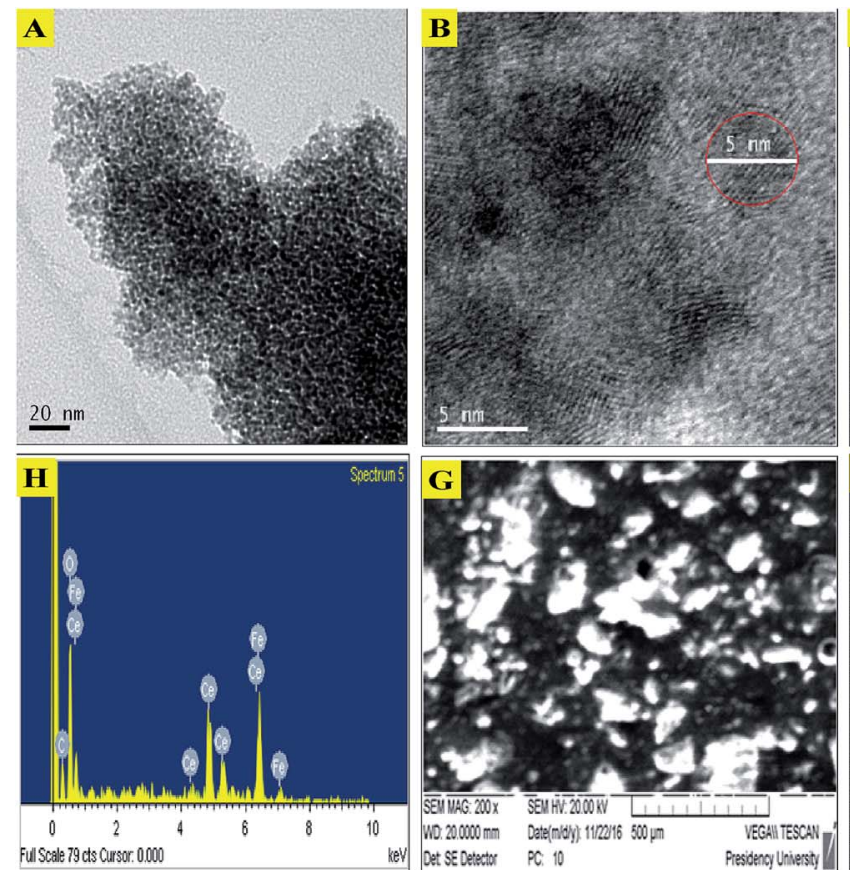
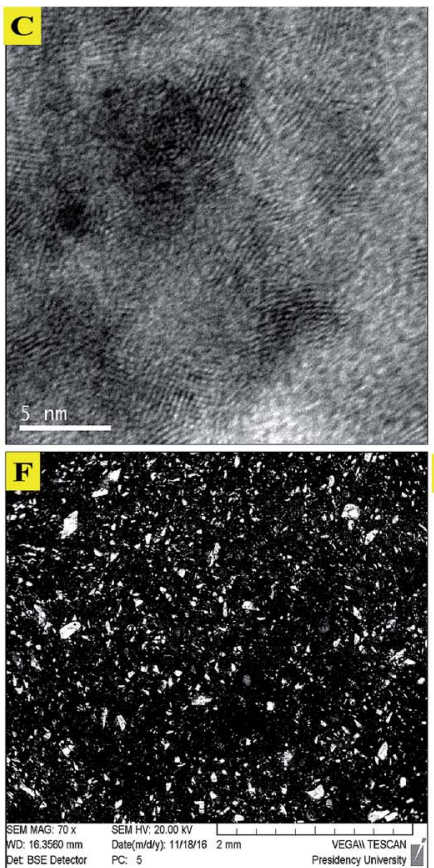
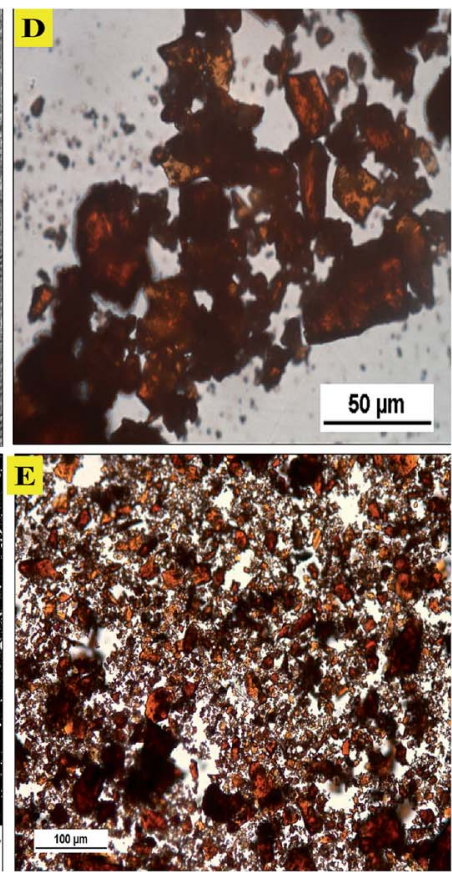

Fig. 2 Transmission electron microscopy images of CIHFO at different magnifications: (A) $20 \mathrm{~nm}$, (B) $5 \mathrm{~nm}$, and (C) $5 \mathrm{~nm}$ showing fingerprint-like impressions of internal crystallinity. Optical microscopy images of the material at (D) high resolution (50 $\mu \mathrm{m}$ scale) and (E) low resolution (100 $\mu \mathrm{m}$ scale). Scanning electron microscopy images of the material at (F) high magnification and (G) low magnification. (H) EDX spectra (a larger image is provided in the ESI (Fig. $S_{5} \dagger$ ) for clarity).

showed multiple band structures at $\nu=1318$ and $1396 \mathrm{~cm}^{-1}$; this confirms the presence of $\mathrm{Fe}-\mathrm{O}-\mathrm{Ce}$ bonds in the material. The TG spectrum of CIHFO (Fig. 3B) recorded a maximum weight loss at around $230^{\circ} \mathrm{C}$, and the percentage of this loss is about 25. This result is different from that of Yang et al. ${ }^{21}$ The weight loss was also confirmed from a sharp exothermic band in the DT spectrum (Fig. 3B). This result is presumably owing to the elimination of physically attached water molecules, including surface-adhered hydrogen bonded and lattice water molecules.

Fig. 4 shows AFM images in 3D (image-A) and 2D (imageB), including the height histogram along the $z$-axis (C), the extracted profile (D), and the length measurement (E). It can be seen that the material has a regular surface morphology with high porosity, a pore volume of $21.4 \AA$ and a pore size distribution with a surface area of $140.711 \mathrm{~m}^{2} \mathrm{~g}^{-1}$. Fig. $\mathrm{S}_{2} \dagger$
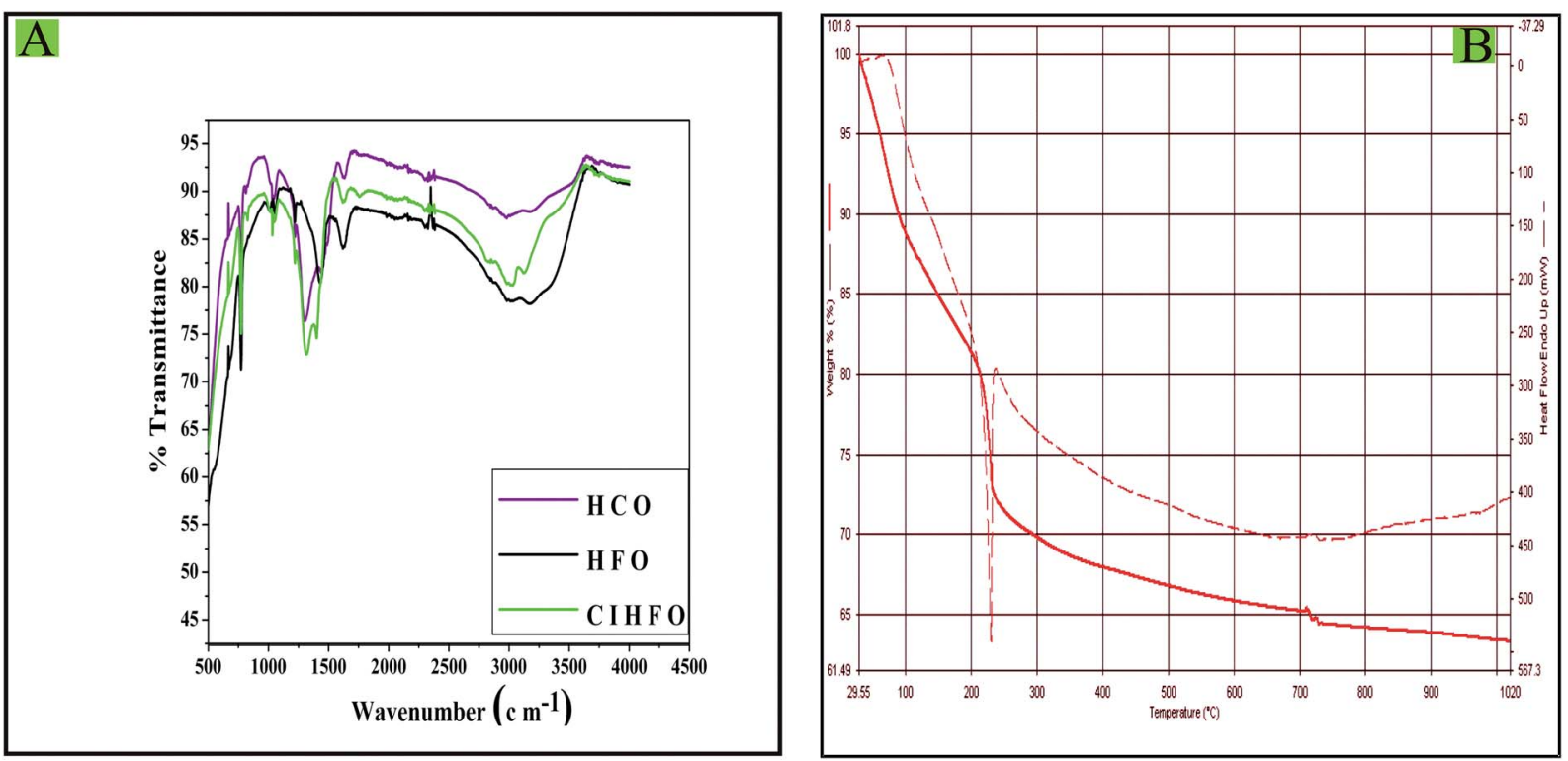

Fig. 3 (A) Fourier transform infrared spectra of HCO, HFO and CIHFO; (B) TGA and DTA spectra of CIHFO. 
shows the plot of $P / P_{0}$ versus $1 /\left[W\left(P_{0} / P\right)-1\right]$; this plot shows a linear change, possibly due to the high porosity of the material.

The plot of $\Delta \mathrm{pH}$ versus $\mathrm{pH}_{\mathrm{i}}$ is shown in Fig. 5A; this plot optimizes the zero point surface charge $\mathrm{pH}\left(\mathrm{pH}_{\mathrm{zpc}}\right)^{32}$ of the material, where a transition of the surface charge occurs from positive to negative via the electrically neutral surface at pH 5.2.

\section{3. $\quad$ Effect of $\mathbf{p H}$}

Fluoride adsorption over an oxide surface is initially influenced by the $\mathrm{pH}$ of the solution $\left(\mathrm{pH}_{\mathrm{i}}\right)$ and the $\mathrm{pH}_{\mathrm{zpc}}$ of the material. In general, anion adsorption is believed to be associated with exchange of hydroxyl ions $\left(\mathrm{OH}^{-}\right)$or coulombic forces; hence, adsorption of fluoride over the surface of CIHFO occurs preferentially at a lower $\mathrm{pH}$ range. The influence of $\mathrm{pH}_{\mathrm{i}}$ upon the fluoride adsorption process over the CIHFO surface is shown in Fig. 5B. It can be seen from the results that the fluoride adsorption capacity $\left(Q_{\mathrm{e}}, \mathrm{mg} \mathrm{g}^{-1}\right)$ decreased with increasing $\mathrm{pH}_{\mathrm{i}}$ from 3.0 to 5.0 and remained almost the same up to $\mathrm{pH}_{\mathrm{i}}$ 7.0. The $Q_{\mathrm{e}}$ value $\left(\mathrm{mg} \mathrm{g}^{-1}\right)$ declined sharply with increasing $\mathrm{pH}_{\mathrm{i}}$ from $>7.0$ to 10.0. A similar $\mathrm{pH}$ effect with a defluoridation process was also reported by Biswas et al. ${ }^{4}$ This indicates that the asprepared material could be profitably used as a fluoride scavenger from water in the $\mathrm{pH}_{\mathrm{i}}$ range from 5.0 to 7.0 .
Fluoride adsorption over the prepared material (CIHFO) can be stipulated by a two-step ligand/anion exchange reaction, $\left(\mathrm{R}_{1}\right)$.

$$
\mathrm{M}-\mathrm{OH}_{2}^{+}+\mathrm{F}^{-} \rightarrow \mathrm{M}-\mathrm{F}+\mathrm{H}_{2} \mathrm{O}
$$

At strongly acidic $\mathrm{pH}\left(\mathrm{pH}_{\mathrm{i}}=3\right)$, the high value of $Q_{\mathrm{e}}$ is due to the electrostatic/columbic attraction forces of fluoride to the positively charged surface of the material. The decrease in $Q_{\mathrm{e}}$ with increasing $\mathrm{pH}_{\mathrm{i}}$ from 3.0 to 5.0 is due to the fluctuation of the positive charge density of the solid surface. When $\mathrm{pH}=$ $\mathrm{pH}_{\mathrm{ZPC}}(5.2 \pm 0.2)$, the solid oxide surfaces are electrically neutral; this is attributed to the equal distribution of positive and negative charges. Fluoride adsorption in these conditions can be simply explained by reaction $\left(\mathrm{R}_{2}\right)$.

$$
\mathrm{M}-\mathrm{OH}+\mathrm{F}^{-} \rightarrow \mathrm{M}-\mathrm{F}+\mathrm{OH}^{-}
$$

When $\mathrm{pH}_{\mathrm{i}}>\mathrm{pH}_{\mathrm{ZPC}}(5.2 \pm 0.2)$, the CIHFO surface becomes negative and imparts coulombic repulsion to the fluoride ions. Hence, the value of $Q_{\mathrm{e}}\left(\mathrm{mg} \mathrm{g}^{-1}\right)$ started to decline at $\mathrm{pH}_{\mathrm{i}}>7.0$; this can be demonstrated by $\left(\mathrm{R}_{3}\right)$. This situation is in good agreement with the observed noticeable decrease of the equilibrium solution $\mathrm{pH}$.

$$
\mathrm{M}-\mathrm{OH}+\mathrm{F}^{-}+\mathrm{OH}^{-} \rightarrow \mathrm{M}-\mathrm{O}^{-}+\mathrm{F}^{-}+\mathrm{OH}_{2}
$$

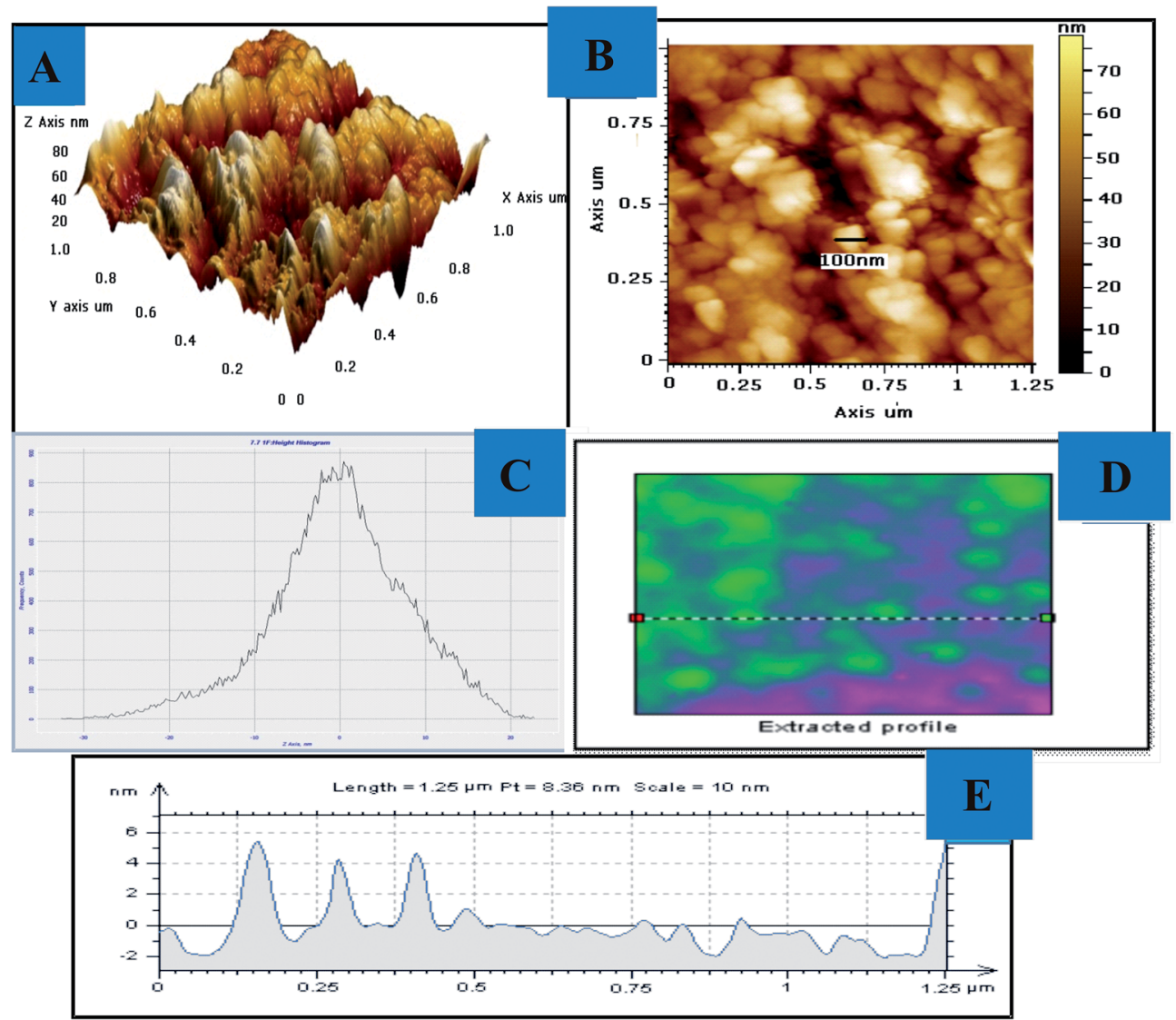

Fig. 4 Atomic force microscopy images of CIHFO: (A) 3-D view, (B) 2-D view, (C) height histrogram along the Z-axis, and (D) extracted profile, (E) length measurement. 

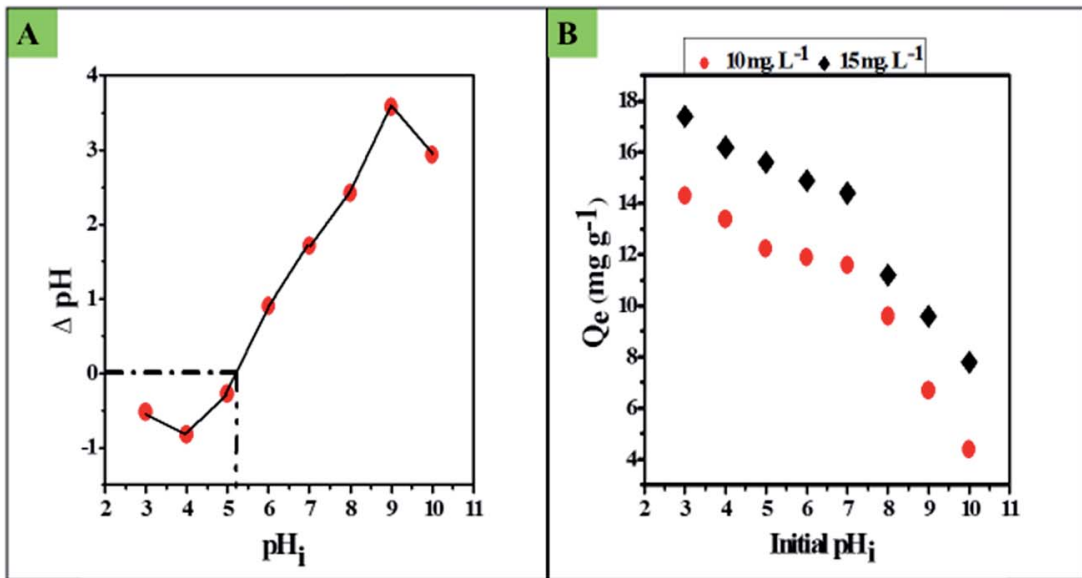

Fig. 5 (A) Plot of $\Delta \mathrm{pH}$ versus $\mathrm{pH}_{\mathrm{i}}$ for estimation of the $\mathrm{pH}_{\mathrm{ZPC}}$ of $\mathrm{ClHFO}$. (B) Effect of the initial solution $\mathrm{pH}$ on the adsorption of fluoride over the surface of $\mathrm{CIHFO}$ at $303 \mathrm{~K}$ with two different fluoride solution concentrations $\left(C_{\mathrm{i}}=10\right.$ and $\left.15 \mathrm{mg} \mathrm{L}^{-1}\right)$.

Hence, in a lower $\mathrm{pH}$ range, especially below $\mathrm{pH}_{\mathrm{PZC}}$, the dominating positive charge over the solid surface triggers quick adsorption of the fluoride ions from the solution onto the solid surface due to columbic forces; this elucidates the increase in the adsorption capacity. It is obvious that CIHFO may be an efficient scavenger of fluoride; this is in good agreement with results of other researchers, ${ }^{4}$ who also observed enhanced adsorption of fluoride with decreasing $\mathrm{pH}$.

\subsection{Effect of CIHFO dose}

To determine the effects of the adsorbent dose on fluoride removal, the adsorbent dose was varied from 0.05 to $2.0 \mathrm{~g}$ per 50 mL fluoride solution with $C_{\mathrm{i}}=10.0,15.0$ or $20.0 \mathrm{mg} \mathrm{\textrm {L } ^ { - 1 }}$, respectively, for the adsorption reaction at $30{ }^{\circ} \mathrm{C}(303 \mathrm{~K})$ and at $\mathrm{pH}_{\mathrm{i}} \sim 7.0$. It was noticed that the fluoride removal capacity $\left(Q_{\mathrm{e}}, \mathrm{mg} \mathrm{g}^{-1}\right)$ decreased for a given $C_{\mathrm{i}}$ value with increasing adsorbent dose (Fig. 6). This phenomenon can be elucidated by the surface site heterogeneity model. As per this model, surface sites are composed of a series of spectra of binding energies. When the dose is applied in minute quantity, the availability of exposed surface sites increases the adsorption capacity $\left(Q_{\mathrm{e}}\right)$ value. This condition reversed as the adsorbent dose was increased, which is similar to other studies.,15,23,25

\subsection{Kinetic modelling}

The time-dependent adsorption capacity values, $Q_{t}\left(\mathrm{mg} \mathrm{g}^{-1}\right)$, with increasing reaction time are presented in Fig. 7A-F. Here, A to C represent the $Q_{t}$ data, respectively, for the adsorption of fluoride by CIHFO at reaction temperatures of $20^{\circ} \mathrm{C}(293), 30^{\circ} \mathrm{C}$ (303) and $40{ }^{\circ} \mathrm{C}(313 \mathrm{~K})$; (D) to (F) represent the $Q_{t}$ data obtained for fluoride solutions with $C_{\mathrm{i}}=10.0,15.0$ and $20.0 \mathrm{mg} \mathrm{L}^{-1}$ at 303 $\mathrm{K}$ and $\mathrm{pH} \sim 7.0$. Inspection of the data revealed that more than $80 \%$ of the loaded fluoride transferred to the material surface from the solution in $t=0$ to 40 minutes; the remaining $15 \%$ to $20 \%$ of the fluoride in solution required more time to transfer onto the solid surface. This later slow solute transfer may be due to coulombic and physical hindrance from the fluoride already transferred to the solid surface from the solution as well as decreases of the available solute concentration and the adsorption sites of the adsorbent. ${ }^{15,23,25}$

The kinetic data shown in Fig. 7 were analysed by the commonly used pseudo-first order (eqn (2)), pseudo-second order (eqn (3)), and intra-particle diffusion (eqn (4)) model equations; $;^{\mathbf{4}, \mathbf{3 3}}$ these well-known theoretical concepts are generally applied to understand the mechanism of fluoride adsorption on an adsorbent.

$$
\begin{gathered}
Q_{t}=Q_{\mathrm{e}}\left[1-\mathrm{e}^{-k_{1} t}\right] \\
Q_{t}=t \times k_{2} \times Q_{\mathrm{e}}^{2} /\left[1+\left(t \times k_{2} \times Q_{\mathrm{e}}\right)\right] \\
Q_{t}=K_{\mathrm{id}} t^{0.5}+C
\end{gathered}
$$

where $Q_{\mathrm{e}}\left(\mathrm{mg} \mathrm{g}^{-1}\right)$ and $Q_{t}\left(\mathrm{mg} \mathrm{g}^{-1}\right)$ are the amounts of fluoride adsorbed by CIHFO at equilibrium at any time $t$ (min); $k_{1}$ $\left(\min ^{-1}\right), k_{2}\left(\mathrm{~g} \mathrm{mg}^{-1} \min ^{-1}\right)$ and $K_{\mathrm{id}}$ represent the pseudo-first order, pseudo-second order and intra-particle diffusion rate constants, respectively; and $C$ represents the boundary layer thickness. The non-linear plots of the kinetic data with pseudofirst order (dotted line) and pseudo-second order (bold line) model fits are also shown in Fig. 7A-F. The parameters of the kinetic model eqn (2) and (3) as estimated from the plots are demonstrated in Table 1. Considering the values of the regression coefficient $\left(R^{2}\right)$ and the statistical error chi-square $\left(\chi^{2}\right)$, it can be observed that fluoride adsorption over the CIHFO surface occurred almost in accordance with both the pseudofirst and pseudo-second order models. ${ }^{29-31}$ The $Q_{t(\exp )}$ values were found to be very close to the modelled $Q_{t}$ value from the pseudo-second order kinetics model at any particular time and temperature. It can be assumed from these results that the fluoride adsorption process can be well fitted with the pseudosecond order model; hence, the adsorption process proceeds by a chemisorption mechanism. ${ }^{11,31}$

An increase of the rate of a reaction with temperature is associated with the availability of more fractions of adsorbent species with the threshold energy required for effective 


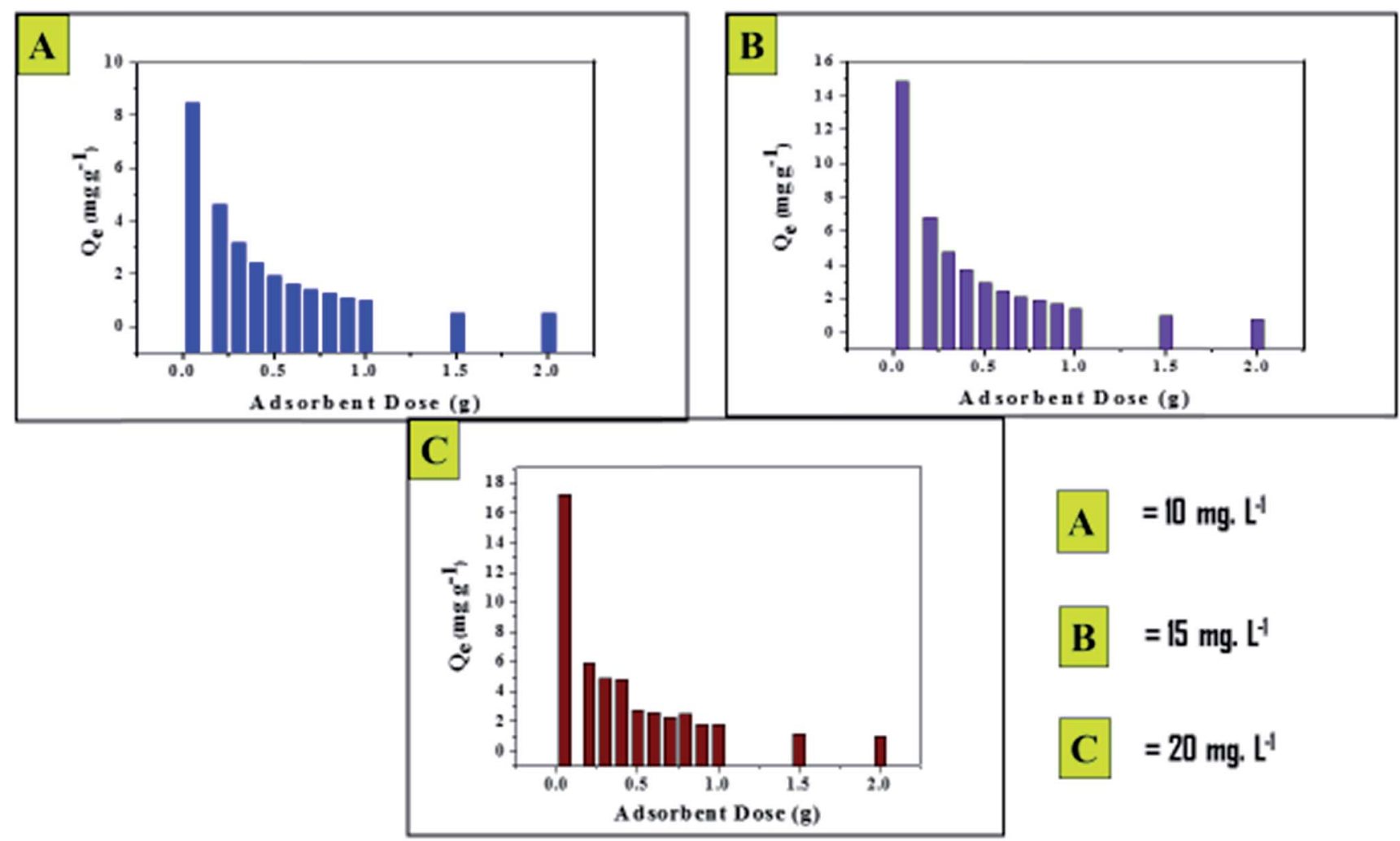

Fig. 6 Effects of adsorbent dose on fluoride removal at three different concentrations at $\mathrm{pH} 7.0( \pm 2)$ and a temperature of $303 \mathrm{~K}\left( \pm 2{ }^{\circ} \mathrm{C}\right)$ with a contact time of $120 \mathrm{~min}$.

molecular collision..$^{34}$ It was observed that the value of $Q_{t}$ decreased with increasing reaction temperature. The decrease of the value of $Q_{t}$ with increasing temperature indicates the exothermic nature of the adsorption reaction. In the case of increasing $C_{\mathrm{i}}$, the rate change showed a similar result; however, the value of $Q_{t}$ decreased with decreasing value of $C_{\mathrm{i}}$. This is presumably due to the increased availability of solute loading sites per unit of the active sites.

As per the intra-particle diffusion model, the plot of $Q_{t}$ against $t^{0.5}$ (Weber-Morris plot) ${ }^{33}$ should be a straight line with a non-zero intercept value or a combination of two or three straight lines including the origin as a point. However, the present $Q_{t}$ data acquired under our experimental conditions and at the investigated $C_{\mathrm{i}}$ of fluoride when plotted against $t^{0.5}$ demonstrated a straight line with a good $R^{2}$ value (Fig. 7G-I), indicating that fluoride adsorption over CIHFO occurred via a boundary layer (film) diffusion process. ${ }^{33}$ The boundary layer (film) diffusion process was also indicated when the temperature-dependent $Q_{t}$ data were plotted against $t^{0.5}$ (see ESI, Fig. $S_{3} \dagger$ ).

\subsection{Equilibrium analysis}

To determine the adsorption efficacy of a newly developed adsorbent, adsorption isotherms are basic requirements for the commercialisation of the adsorption system. Langmuir and Freundlich are two fundamental isotherm models that can conveniently depict the surface properties and adsorption mechanism of such a system. Fig. 8A-C presents the equilibrium data for the adsorption of fluoride on CIHFO at $\mathrm{pH} \sim 7.0$ and at temperatures of $293( \pm 2) \mathrm{K}, 303( \pm 2) \mathrm{K}$, and $313( \pm 2) \mathrm{K}$, respectively. We examined the adherence of the equilibrium data to the most widely accepted isotherm models, namely Langmuir $^{35}$ (bold line) (eqn (5)), Freundlich ${ }^{36}$ (dotted line) (eqn (6)) and Redlich-Peterson ${ }^{37}$ (inset) (eqn (7)) (Fig. 8A-C). The Langmuir model assumes that each molecule retains the same adsorption energy, there is no interaction between the molecules and all sites have equal affinities towards the adsorbate; hence, this isotherm denotes homogeneous adsorption. The Freundlich model is associated with non-ideal multilayer adsorption and heterogeneity of the adsorption sites. The nonlinear expressions of the Langmuir, Freundlich and RedlichPeterson eqn (5)-(7) can be set as

$$
\begin{gathered}
Q_{\mathrm{e}}=q_{\mathrm{m}} \times K_{\mathrm{L}} \times C_{\mathrm{e}}\left(1+K_{\mathrm{L}} \times C_{\mathrm{e}}\right) \\
Q_{\mathrm{e}}=K_{\mathrm{F}} \times C_{\mathrm{e}}^{1 / n} \\
Q_{\mathrm{e}}=\alpha C_{\mathrm{e}} / 1+\beta C_{\mathrm{e}}^{g}
\end{gathered}
$$

where $C_{\mathrm{e}}\left(\mathrm{mg} \mathrm{L}^{-1}\right)$ and $Q_{\mathrm{e}}\left(\mathrm{mg} \mathrm{g}^{-1}\right)$ are the equilibrium fluoride concentration and equilibrium adsorption capacity, respectively. The $q_{\mathrm{m}}$ value $\left(\mathrm{mg} \mathrm{g}^{-1}\right)$ is the maximum monolayer adsorption capacity $\left(\mathrm{mg} \mathrm{g}^{-1}\right)$, and $K_{\mathrm{L}}\left(\mathrm{L} \mathrm{mg}^{-1}\right)$ is the equilibrium constant related to the net enthalpy change of the reaction. $K_{\mathrm{F}}$ is the Freundlich adsorption capacity, and $1 / n$ is an 


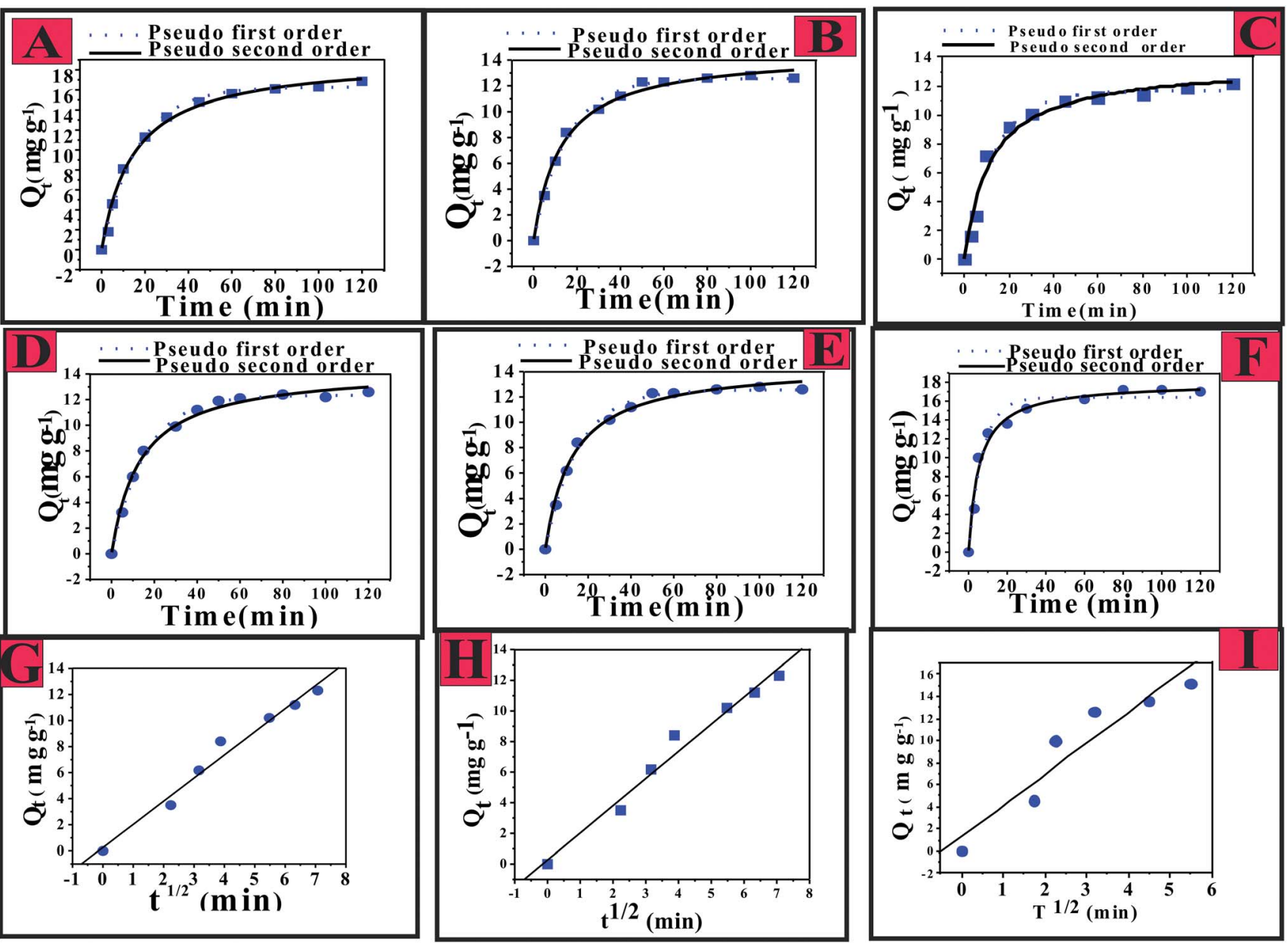

Fig. 7 The plots of fluoride adsorption capacity at any time and $Q_{t}\left(\mathrm{mg} \mathrm{g}^{-1}\right)$ versus time, $t$ (min) including non-linear pseudo-first order (-- - ) and pseudo-second order (-) plots at three different temperatures, (A) $293 \mathrm{~K}$, (B) $303 \mathrm{~K}$ and (C) $313 \mathrm{~K}$, with an active fluoride concentration of $10 \mathrm{mg} \mathrm{L}^{-1}$ (ionic strength $=1 \mathrm{M}$ ) at $\mathrm{pH} 7.0$ and also with three fluoride solutions with different concentrations, (D) $C_{\mathrm{i}}=10.0 \mathrm{mg} \mathrm{L} \mathrm{L}^{-1},(\mathrm{E}) C_{\mathrm{i}}=$ $15.0 \mathrm{mg} \mathrm{L}^{-1}$ and $(F) C_{i}=20.0 \mathrm{mg} \mathrm{L}^{-1}$, at a temperature of $303 \mathrm{~K}$ (ionic strength $=1 \mathrm{M}$ ) and pH 7.0. The plots of $Q_{t}\left(\mathrm{mg} \mathrm{g}^{-1}\right.$ ) versus $t^{1 / 2}$ (min) for three different fluoride concentrations, (G) $10.0 \mathrm{mg} \mathrm{L}^{-1},(\mathrm{H}) 15.0 \mathrm{mg} \mathrm{L}^{-1}$ and (I) $20.0 \mathrm{mg} \mathrm{L}^{-1}$, at a temperature of $303 \mathrm{~K}$ (ionic strength $=1 \mathrm{M}$ ) and $\mathrm{pH} 7.0$.

Table 1 Estimated kinetic parameters for fluoride adsorption reactions with $\mathrm{ClHFO}$ at $\mathrm{pH}=7.0( \pm 0.2)$ at 293,303 and $313 \mathrm{~K}$

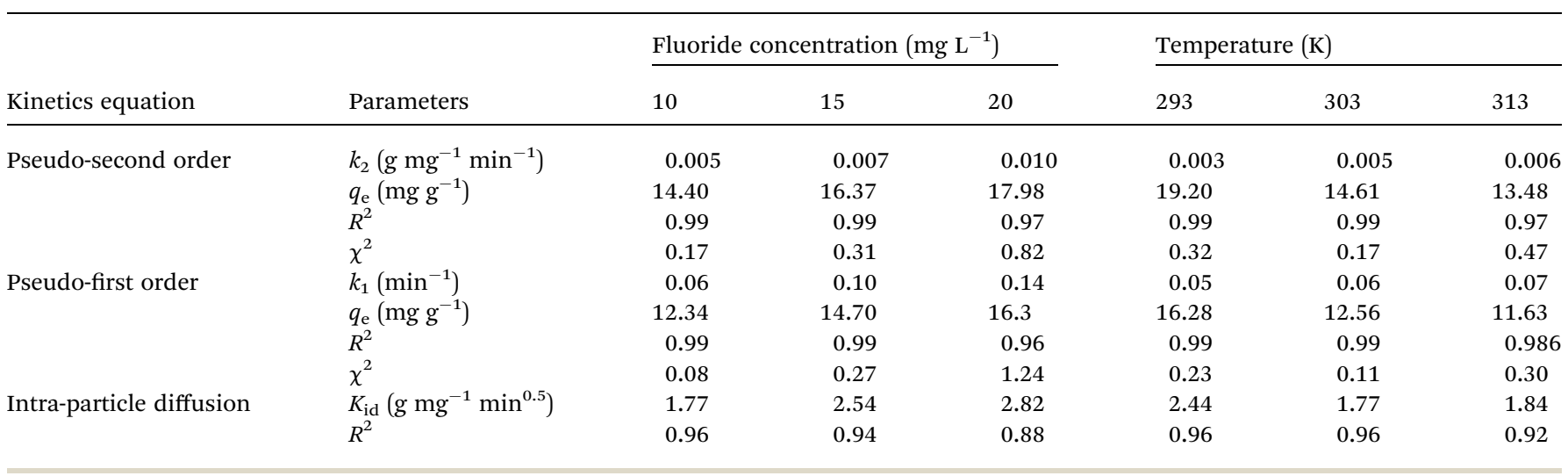

empirical constant related to the adsorption intensity; $\alpha, \beta$ and $g$ are the constants of the three-parameter Redlich-Peterson isotherm equation, which bears characteristics of both the
Langmuir and Freundlich isotherm models. (i) When the value of $g$ moves to 1, eqn (7) converts to the Langmuir form; (ii) when $g$ increases to below unity but is greater than zero, eqn (7) 

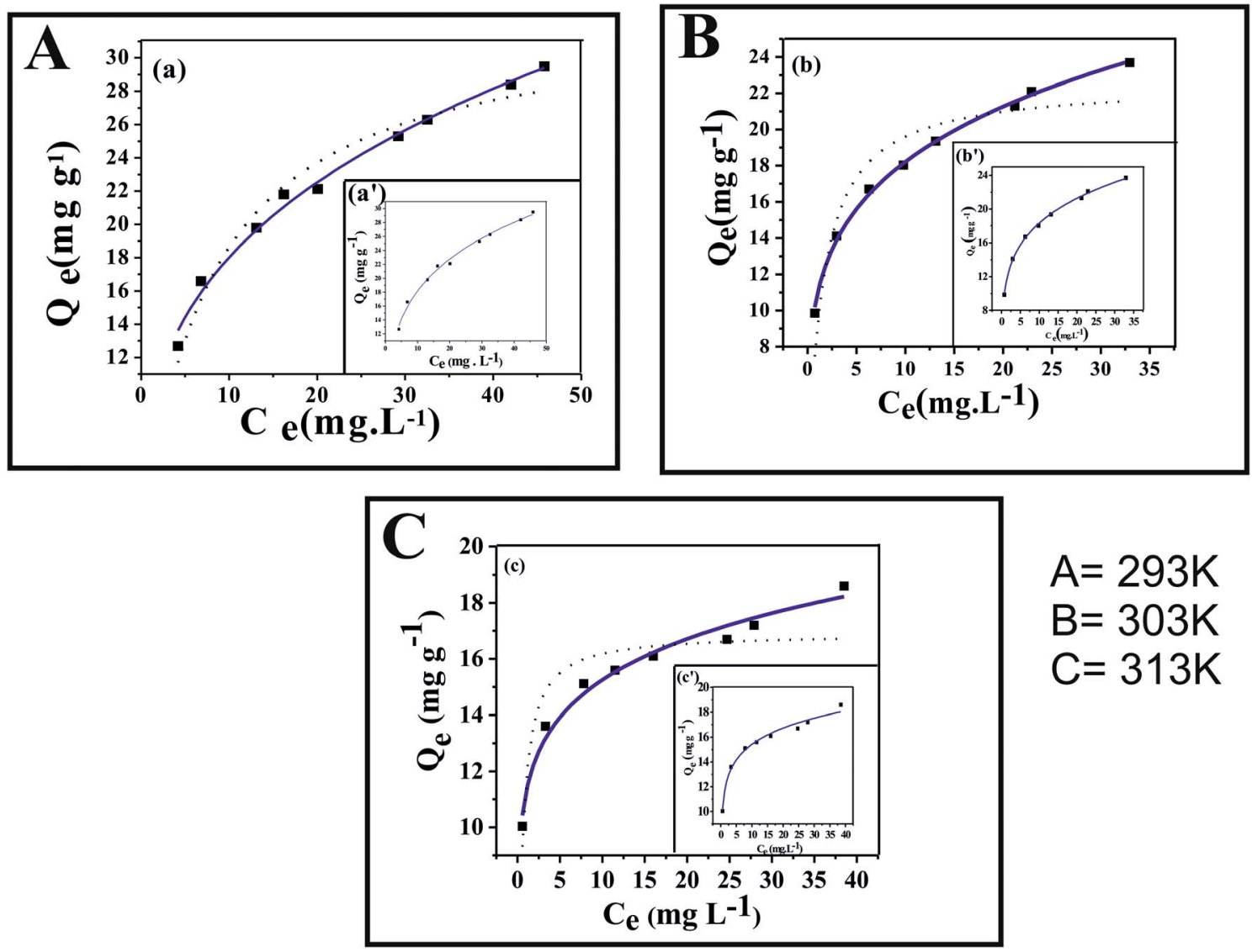

Fig. 8 (A) Adsorption isotherm plots and model fits: (a) Freundlich, Langmuir and (a') Redlich-Peterson (inset) at 293 K; (B) adsorption isotherm plots and model fits: (b) Freundlich, Langmuir and ( $b^{\prime}$ ) Redlich-Peterson (inset) at $303 \mathrm{~K}$; (C) adsorption isotherm plots and model fits: (c) Freundlich, Langmuir and ( $\left.c^{\prime}\right)$ Redlich-Peterson fitting (inset) at $313 \mathrm{~K}$.

converts to the Freundlich form; and (ii) when $g$ moves to zero, eqn (7) converts to Henry's form. ${ }^{37}$

The isotherm parameters generated from the plots of the equilibrium data on the origin using spreadsheet software are presented in Table 2. From the values of the regression coefficient $\left(R^{2}\right)$ and the statistical error chi-square $\left(\chi^{2}\right)$ of non-linear analysis, it can be seen that the equilibrium data fit much better with the Freundlich model than with the Langmuir model. For further confirmation of the better Freundlich fit, the equilibrium data was also analysed with the Redlich-Peterson isotherm model (inset, Fig. 8); the as-estimated model parameters are also given in Table 2. Here, the value of $g$ was found to be somewhat away from unity, confirming the greater conformity of the equilibrium data with the Freundlich isotherm..$^{37}$

The evaluated degree of the Freundlich coefficient $(1 / n)$ falls between 0 and 1 , as the values of $n$ obtained are 3.10, 4.47 and 7.57 , respectively for the temperatures ( $293 \mathrm{~K}, 303 \mathrm{~K}$ and $313 \mathrm{~K}$ ) applied in the equilibrium reactions. Again, the high value of $n$ validated that the fluoride uptake by CIHFO followed the Freundlich isotherm more than the Langmuir isotherm. ${ }^{13}$ Thus, it can be said that the adsorption sites of this mixed metal oxide are heterogeneous, and the multilayer adsorption mechanism is suitable for the fluoride adsorption.

The Dubinin-Radushkevich (D-R) equation (eqn (8)) $)^{38,39}$ was used to evaluate the free energy of the reaction; it can be obtained from the equilibrium isotherm data to predict whether the nature of adsorption is physical, ion-exchange or chemical.

$$
\ln Q_{\mathrm{e}}=\ln Q_{\mathrm{m}}-\beta \varepsilon^{2}
$$

where $Q_{\mathrm{e}}$ and $Q_{\mathrm{m}}$ are the equilibrium and maximum D-R adsorption capacities $\left(\mathrm{mol} \mathrm{kg}^{-1}\right)$, respectively, whereas $\beta$ signifies the activity coefficient that is related to the mean free energy $\left(\mathrm{mol}^{2} \mathrm{~kJ}^{-2}\right)$ of the reaction. As eqn (8) represents the equation of a straight line, the plot of $\ln Q_{\mathrm{e}}$ against $\varepsilon^{2}$ becomes a straight line, and the values of the slope and intercept of the plot (Fig. $\mathrm{S}_{4} \dagger$ ) were used to calculate the values of $\beta$ and $Q_{\mathrm{m}}$ (Table 2).

$\varepsilon$ is the Polanyi potential, which can be extracted from eqn (9) below:

$$
\varepsilon=R T \ln \left(1+1 / C_{\mathrm{e}}\right)
$$

where $R$ is the molar gas constant $\left(8.314 \mathrm{~J} \mathrm{~mol}^{-1} \mathrm{~K}^{-1}\right)$ and $T$ is the absolute temperature $(\mathrm{K})$. The mean free energy change is basically the change of free energy required to transform the adsorbate molecule from infinity to the adsorbent surface. ${ }^{40}$ The values of $E_{\mathrm{DR}}$ were calculated from eqn (10) and are incorporated in Table 2. 
Table 2 Isotherm parameters of fluoride adsorption reactions with $\mathrm{CIHFO}$ at $\mathrm{pH}=7.0( \pm 0.2)$ at 293,303 and $313 \mathrm{~K}$

\begin{tabular}{|c|c|c|c|c|}
\hline \multirow[b]{2}{*}{ Isotherm model } & \multirow[b]{2}{*}{ Parameters } & \multicolumn{3}{|c|}{ Temperature } \\
\hline & & $293 \mathrm{~K}$ & $303 \mathrm{~K}$ & $313 \mathrm{~K}$ \\
\hline \multirow[t]{4}{*}{ Langmuir } & $\theta\left(\mathrm{mg} \mathrm{g}^{-1}\right)$ & 32.62 & 22.55 & 16.91 \\
\hline & $K\left(\mathrm{~L} \mathrm{mg}^{-1}\right)$ & 0.13 & 0.66 & 2.18 \\
\hline & $\chi^{2}$ & 1.29 & 2.88 & 1.20 \\
\hline & $R^{2}$ & 0.96 & 0.88 & 0.84 \\
\hline \multirow[t]{4}{*}{ Freundlich } & $n$ & 3.10 & 4.47 & 7.57 \\
\hline & $K_{\mathrm{F}}\left(\mathrm{mg} \mathrm{g}^{-1}\right)$ & 8.58 & 10.88 & 11.25 \\
\hline & $R^{2}$ & 0.99 & 0.99 & 0.98 \\
\hline & $\chi^{2}$ & 0.31 & 0.05 & 0.15 \\
\hline \multirow[t]{5}{*}{ Redlich-Peterson } & $\alpha$ & 16.25 & 156.29 & 170.47 \\
\hline & $\beta$ & 1.44 & 13.5 & 14.16 \\
\hline & $g$ & 0.74 & 0.79 & 0.88 \\
\hline & $R^{2}$ & 0.99 & 0.99 & 0.98 \\
\hline & $\chi^{2}$ & 0.28 & 0.03 & 0.13 \\
\hline \multirow[t]{4}{*}{ Dubinin-Radushkevich } & $\hat{Q}_{\mathrm{m}}\left(\mathrm{mol} \mathrm{kg}^{-1}\right)$ & 3.05 & 2.07 & 1.29 \\
\hline & $\beta\left(\mathrm{mol}^{2} \mathrm{~kJ}^{-2}\right) \times 10^{3}$ & 3.14 & 2.08 & 1.21 \\
\hline & $E_{\mathrm{DR}}\left(\mathrm{kJ} \mathrm{mol}^{-1}\right)$ & 12.61 & 15.50 & 20.32 \\
\hline & $R^{2}$ & 0.60 & 0.96 & 0.98 \\
\hline
\end{tabular}

$$
E_{\mathrm{DR}}=1 /(2 \beta)^{1 / 2}
$$

It can be seen that the values of $Q_{\mathrm{m}}$ decreased with increasing temperature, which supports the previous results obtained from equilibrium modelling. From the D-R equation and according to the value of $E_{\mathrm{DR}}$, an adsorption process may be one of three types: ${ }^{38-40}$ (i) physisorption if $E_{\mathrm{DR}}=8.0 \mathrm{~kJ}$ $\mathrm{mol}^{-1}$, (ii) ion-exchange if $E_{\mathrm{DR}}=8.0$ to $16.0 \mathrm{~kJ} \mathrm{~mol}^{-1}$ and (iii) chemisorption if $E_{\mathrm{DR}}>16.0 \mathrm{~kJ} \mathrm{~mol}^{-1}$. The gradual increase of the $E_{\mathrm{DR}}$ value with increasing temperature from 12.61 to 20.32 $\mathrm{kJ} \mathrm{mol}^{-1}$ indicates that the adsorption of fluoride proceeds from ion-exchange to chemisorption. At $303 \mathrm{~K}$, the $E_{\mathrm{DR}}$ obtained in the present case is $15.50 \mathrm{~kJ} \mathrm{~mol}^{-1}$, which is indicated to be at the borderline of the ion-exchange and chemisorption processes. ${ }^{8,38}$

\subsection{Thermodynamic parameters}

Changes in thermodynamic parameters such as standard free energy $\left(\Delta G^{0}\right)$, standard enthalpy $\left(\Delta H^{0}\right)$ and standard entropy $\left(\Delta S^{0}\right)$ for this adsorption process were estimated using the following thermodynamic relations (eqn (11) and (12)), ${ }^{40}$ assuming the activity coefficient to be unity at low solute concentrations.

$$
\Delta G^{0}=\Delta H^{0}-T \Delta S^{0}
$$

and

$$
\Delta G^{0}=-2.303 R T \log K_{\mathrm{c}}
$$

From eqn (11) and (12), eqn (13) can be derived:

$$
\log K_{\mathrm{c}}=\Delta S^{0} / 2.303 R-\left(\Delta H^{0} / 2.303 R\right) 1 / T
$$

Every term in the context represented herewith has its usual significance. Eqn (14) is adapted from eqn (13) with a slight alteration, where the thermodynamic equilibrium constant $K_{\mathrm{c}}$ is substituted by $q_{\mathrm{e}} / C_{\mathrm{e}}$ :

$$
\log \left(q_{\mathrm{e}} / C_{\mathrm{e}}\right)=\Delta S^{0} / 2.303 R-\left(\Delta H^{0} / 2.303 R\right) 1 / T
$$

$\Delta S^{0}$ and $\Delta H^{0}$ are constants within the studied temperature range; the values of both constants were computed from the intercept and slope of the straight line of the plot of $\log \left(q_{\mathrm{e}} / C_{\mathrm{e}}\right)$ versus $1 / T$ (Fig. 9A), and $\Delta G^{0}$ at various temperatures was assessed using eqn (12). The plots showed good linearity, as is evident from the high regression coefficient value $\left(R^{2}=0.98\right)$, by taking the $C_{\mathrm{i}}$ of fluoride solution as $35.0 \mathrm{mg} \mathrm{L}^{-1}$; the results are presented in Table 3. The $\Delta G^{0}$ values for fluoride adsorption by CIHFO indicate the thermodynamic feasibility/spontaneity of the reactions. The negative values of $\Delta G^{0}$ (Table 3) confirm that the adsorption of fluoride by CIHFO is spontaneous and can occur in a wide range of temperatures. The highly negative value of $\Delta H^{0}\left(-36.279 \mathrm{~kJ} \mathrm{~mol}^{-1}\right)$ indicates that the adsorption process is also exothermic in nature. ${ }^{11}$ This was in agreement with the results of the isotherm analysis. The entropy change $\left(\Delta S^{0}\right)$ was found to be $-86.537 \mathrm{~J} \mathrm{~mol}^{-1} \mathrm{~K}^{-1}$, indicating the irreversibility and stability of the adsorption process. This thermodynamics pattern has also been reported by other authors. ${ }^{11,14}$

\subsection{Activation energy}

The Arrhenius equation is applicable to evaluate the activation energy of any kind of reaction and can be expressed as eqn (15):

$$
k_{2}=A \exp \left(-E_{\mathrm{a}} / R T\right)
$$

Here, $k_{2}$ is the rate constant $\left(\mathrm{g} \mathrm{mg}^{-1} \mathrm{~min}^{-1}\right), A\left(\mathrm{~g} \mathrm{mg}^{-1} \mathrm{~min}^{-1}\right)$ is a temperature independent factor and $E_{\mathrm{a}}\left(\mathrm{kJ} \mathrm{mol}^{-1}\right)$ is the activation energy of a particular reaction. $R$ and $T$ are well known and were mentioned earlier.

The logarithm of eqn (15) illustrates a linear relationship of the Arrhenius equation and can be drawn as below eqn (16):

$$
\ln k_{2}=\ln A+\left(-E_{\mathrm{a}} / R\right) 1 / T
$$

The plot of $\ln k_{2}$ against $1 / T$ generates a straight line (Fig. 9B); the values of $E_{\mathrm{a}}$ and $A$ were calculated from the slope and intercept of the plot and were found to be $E_{\mathrm{a}}=0.026 \mathrm{~kJ}$ $\mathrm{mol}^{-1}$ and $A=4.95 \mathrm{~g} \mathrm{mg}^{-1} \mathrm{~min}^{-1}$. The significantly low value of the activation energy supports the high fluoride affinity of CIHFO and the feasibility of the reaction. ${ }^{8,41}$

\subsection{Effects of co-occurring ions on fluoride adsorption}

Among commonly occurring groundwater anions, sulphate showed adverse effects on fluoride adsorption by CIHFO. The results of the adverse influence of sulphate on fluoride adsorption from the solution of $C_{\mathrm{i}}=10.0 \mathrm{mg} \mathrm{L}^{-1}$ are shown in Fig. 10A. It can be seen that as the sulphate concentration increased from 10.0 to $150 \mathrm{mg} \mathrm{L}^{-1}$, the fluoride adsorption amount $\left(9.5 \mathrm{mg} \mathrm{g}^{-1}\right)$ decreased to $3.3 \mathrm{mg} \mathrm{g}^{-1}$, which is only $\sim 30 \%$ of the initial value. However, the fluoride adsorption amount $\left(9.5 \mathrm{mg} \mathrm{g}^{-1}\right)$ was 

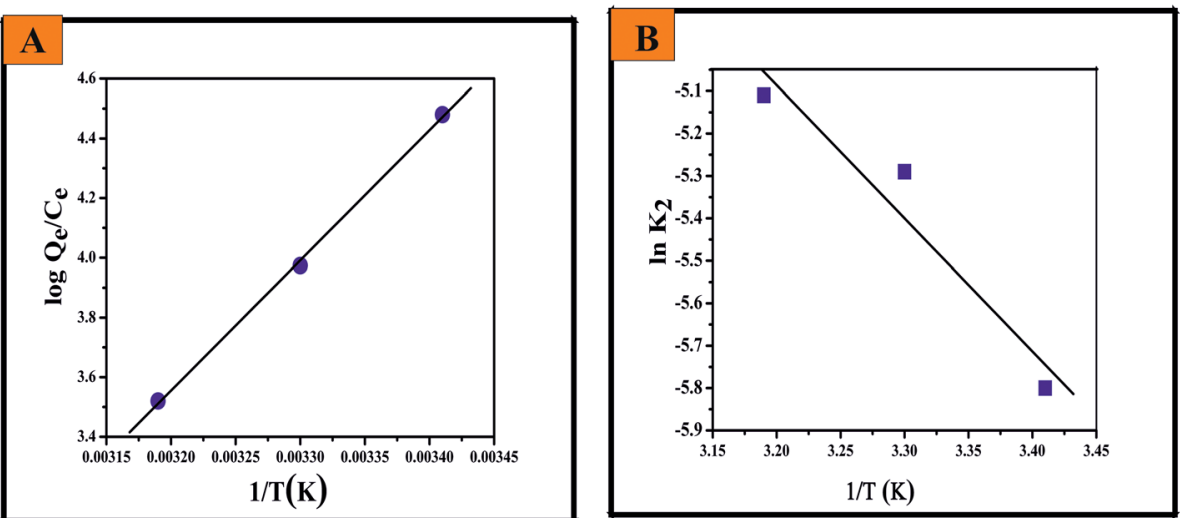

Fig. 9 The plots of $(\mathrm{A}) \log Q_{\mathrm{e}} / C_{\mathrm{e}}$ versus $1 / T(\mathrm{~K})$ for the thermodynamic parameters and $(\mathrm{B}) \ln k_{2}$ versus $1 / T$ (K) for the activation energy of the fluoride adsorption reaction with CIHFO.

Table 3 Thermodynamic parameters for fluoride adsorption reactions with $\mathrm{CIHFO}$ at $\mathrm{pH}=7.0( \pm 0.2)$

\begin{tabular}{llllr}
\hline \multirow{2}{*}{$\begin{array}{l}\text { Fluoride concentration } \\
\left(\mathrm{mg} \mathrm{L}^{-1}\right)\end{array}$} & $\Delta H^{0}\left(\mathrm{~kJ} \mathrm{~mol}^{-1}\right)$ & $\Delta S^{0}\left(\mathrm{~J} \mathrm{~mol}^{-1} \mathrm{~K}^{-1}\right)$ & \multicolumn{2}{c}{$\Delta G^{0}\left(\mathrm{~kJ} \mathrm{~mol}^{-1}\right)$ at different temperatures $(\mathrm{K})$} \\
\hline 25 & -25.924 & -47.411 & 293 & 303 \\
35 & -36.279 & -86.537 & -11.941 & -11.698 \\
\end{tabular}
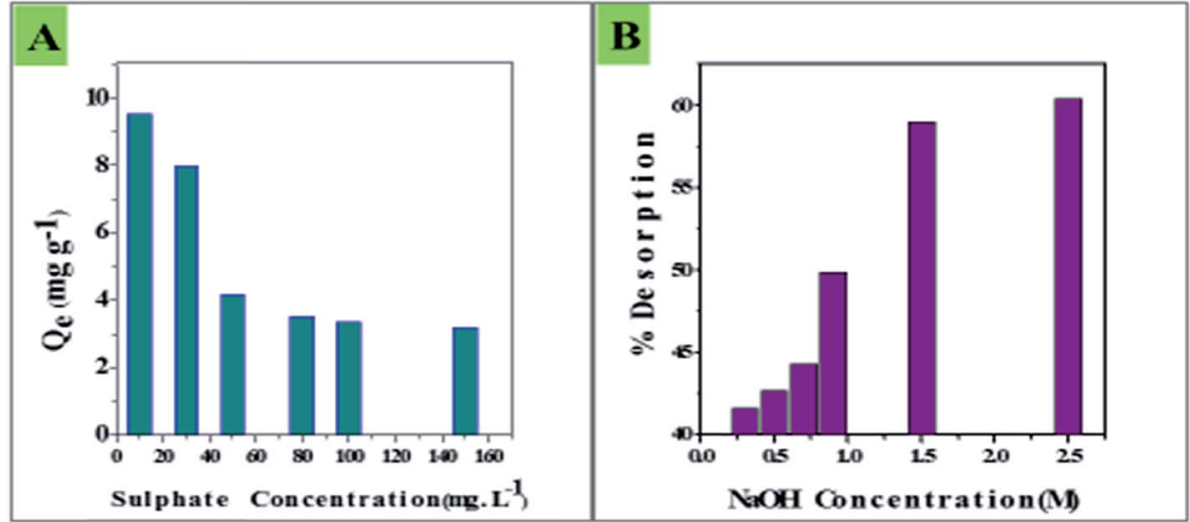

Fig. 10 Effects of (A) sulphate interference on fluoride adsorption by $\mathrm{ClHFO}$ and (B) molar concentration of $\mathrm{NaOH}$ on the desorption of fluoride from the CIHFO surface.

similar in the presence of other anions, such as phosphate, bicarbonate, nitrate and chloride. The sequence of the adverse influence of the tested ions on fluoride adsorption over CIHFO can be given as $\mathrm{SO}_{4}{ }^{2-}, \mathrm{HCO}_{3}{ }^{-}>\mathrm{HPO}_{4}{ }^{2-}>\mathrm{NO}_{3}{ }^{-}>\mathrm{Cl}^{-}$. Some other studies ${ }^{12,20}$ support this interference trend; however, different interference trends have also been reported. ${ }^{6,8}$

\section{Desorption}

From Fig. 10B, it is clear that with increasing basicity, the desorption percentage increased; a maximum of $61 \%$ desorption occurred. A similar increasing trend of desorption percentage with increasing molar strength of base was reported by other researchers. ${ }^{\mathbf{8} 11}$ The process is predicted to be borderline chemisorption and is exothermic in nature; therefore, it is obvious that the product is more stable than the reactant. Also, as the desorption tendency is moderate, the tendency of fluoride to leach into the environment also decreases. The fluoridedesorbed material was found to be recyclable up to a maximum of three cycles, with a drastic decrease of the fluoride absorption efficiency thereafter. 


\section{Fluoride removal from a natural water sample}

Groundwater was collected from a hand pump-attached tubewell in Kharai village (Kashipur block) of Purulia district, West Bengal; the physico-chemical parameters of the groundwater were analysed, including $\mathrm{pH}$ (7.36), iron (total) $0.87 \mathrm{mg}$ $\left.\mathrm{L}^{-1}\right)$, fluoride $\left(9.05 \mathrm{mg} \mathrm{L}^{-1}\right)$, calcium $\left(8.05 \mathrm{mg} \mathrm{L}^{-1}\right)$, magnesium (1.99 $\mathrm{mg} \mathrm{L}^{-1}$ ), hardness (9.99 $\left.\mathrm{mg} \mathrm{L}^{-1}\right)$, TDS (1140 $\mathrm{mg} \mathrm{L}^{-1}$ ), salinity $\left(517 \mathrm{mg} \mathrm{L}^{-1}\right)$, conductivity $(364 \mu \mathrm{S})$ and turbidity (008 NTU). $500 \mathrm{~mL}$ of this water sample was stirred magnetically (500 $\mathrm{rpm}$ ) for 2 hours with increasing CIHFO dosages from $0.1 \mathrm{~g}$ to $1.5 \mathrm{~g}$. Immediately after the experiments, the samples were filtered and the fluoride levels were analyzed. It appeared that the fluoride level was reduced from $9.05 \mathrm{mg} \mathrm{L}^{-1}$ to below $1.0 \mathrm{mg}$ $\mathrm{L}^{-1}$ when the dosage of CIHFO employed was $1.20 \mathrm{~g}$; this is well below the WHO recommended guideline maximum concentration level. Thus, the experimentally approved CIHFO dosage is $2.40 \mathrm{~g} \mathrm{~L}^{-1}$ for the treatment of fluoride-rich (concentration: $9.05 \mathrm{mg} \mathrm{L}^{-1}$ ) groundwater to reduce the fluoride level below $1.0 \mathrm{mg} \mathrm{L}^{-1}$.

\section{Mechanism of fluoride adsorption over CIHFO}

Based on the measured $\mathrm{pH}_{\mathrm{zpc}}$ of CIHFO and the $\mathrm{pH}$ effect on fluoride adsorption, it can be stated that under acidic $\mathrm{pH}$ conditions, more fluoride ions are adsorbed on the adsorbent surface due to electrostatic attractions between the negatively charged adsorbate and the positively charged adsorbent surface. As the energy of activation is low, the fluoride should be distributed very rapidly over the CIHFO surface using the minimum energy which is available from the mechanical agitation of the reaction mixture. The $E_{\mathrm{DR}}$ values $(12.61,15.50$ and $20.32 \mathrm{~kJ} \mathrm{~mol}^{-1}$, respectively, at 293, 303 and $313 \mathrm{~K}$ ) estimated from modelling the equilibrium data with the $\mathrm{D}-\mathrm{R}$ isotherm predict that the adsorption process is ion-exchange to borderline chemisorption. The obtained experimental results indicate that during the adsorption process, the univalent surface hydroxyl ions are exchanged by fluoride ions, leading to the formation of a stable complex with a potential energy lower than that of the reactants (Fig. 11A). The large negative value of $\Delta H^{0}$ and the lower tendency of fluoride desorption support this observation. Moreover, the FTIR spectrum of adsorbed CIHFO when compared with that of CHIFO (Fig. 11B) shows a significant reduction of the $\mathrm{O}-\mathrm{H}$ stretching and bending band intensities, and the near disappearance ${ }^{13}$ of the bands at $1400 \mathrm{~cm}^{-1}$ and $750 \mathrm{~cm}^{-1}$ validates the proposed mechanism.

\section{Conclusion}

Surface-tuned iron(III) oxide with cerium(Iv) oxide (CIHFO) is a highly porous, microcrystalline and amorphous material with a high surface area relative to that of iron(III) oxide. Microscopic images confirmed the presence of microcrystalline particles not only with nanodimensions but also with irregular surface morphologies. Exploration of this thermally stable material ( $473 \mathrm{~K})$ for fluoride adsorption shows that the surface reaction occurs according to pseudo-first as well as pseudo-second order kinetics with a boundary layer (film) diffusion process. The very low Arrhenius energy of activation indicates the high affinity of CIHFO for fluoride. The better adherence of the equilibrium data to the Freundlich isotherm suggests the surface heterogeneity of the CIHFO multilayer adsorption phenomenon. The effects of tested ions on the fluoride adsorption reaction show no notable adverse influence, with the exception of sulphate. The FTIR analysis and other experimental results suggested that fluoride adsorption occurs through an ion-exchange mechanism which ultimately changes to chemisorption. Encouraging results were obtained when CIHFO was employed for high fluoride $\left(9.05 \mathrm{mg} \mathrm{L}^{-1}\right)$ groundwater treatment for field validation.

\section{Acknowledgements}

The authors are grateful to the Head, Department of Chemistry and also to the Department of Geology, including the Authority of the Presidency University, Kolkata, India, for providing laboratory facilities for conducting this work. The authors are thankful to Mr Arijit Halder, SRF, Department of Chemistry, Jadavpur University, Kolkata, for BET analysis. We are thankful
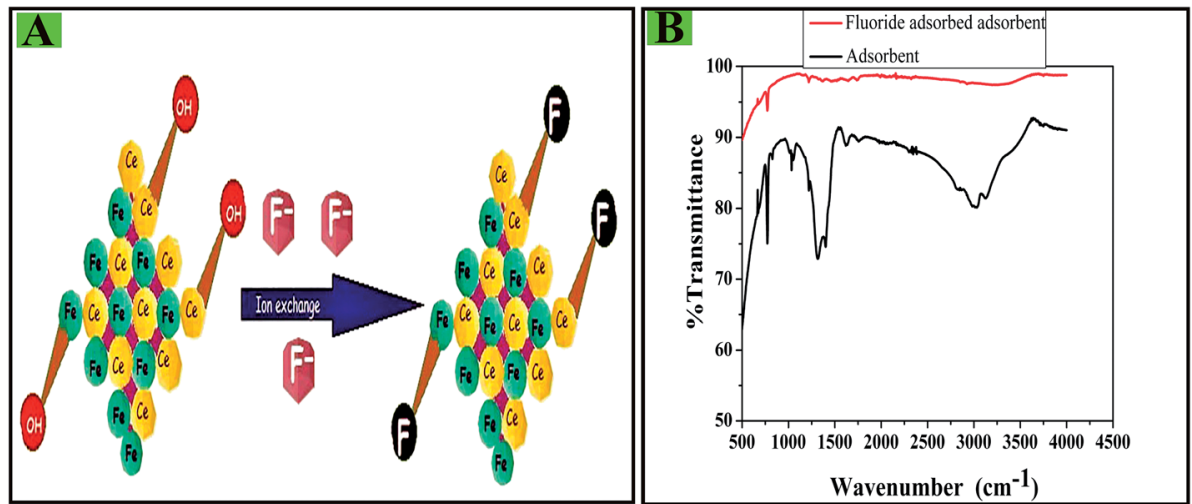

Fig. 11 (A) Schematic of the fluoride adsorption mechanism on the CIHFO surface. (B) Fourier transform infrared spectral data of the pure adsorbent and the fluoride-adsorbed adsorbent. 
to an anonymous reviewer who provided valuable time and comments to help us revise our manuscript into very good shape. The author (K. M.) is grateful to the Department of Science and Technology (DST), Govt. of India for providing her with financial support.

\section{References}

1 D. Fagin, Second thoughts about fluoride, Sci. Am., 2008 Jan 1, 298(1), 74-81.

2 S. Water, Guidelines for drinking-water quality [electronic resource]: incorporating first addendum, World Health Organization, 3rd edn, 2006, vol. 1, Recommendations.

$3 \mathrm{~S}$. Ayoob and A. K. Gupta, Fluoride in drinking water: a review on the status and stress effects, Crit. Rev. Environ. Sci. Technol., 2006 Dec 1, 36(6), 433-487.

4 K. Biswas, K. Gupta and U. C. Ghosh, Adsorption of fluoride by hydrous iron(III)-tin(Iv) bimetal mixed oxide from the aqueous solutions, Chem. Eng. J., 2009 Jul 1, 149(1), 196-206.

5 S. Dey, S. Goswami and U. C. Ghosh, Hydrous ferric oxide (HFO) - a scavenger for fluoride from contaminated water, Water, Air, Soil Pollut., 2004 Oct 1, 158(1), 311-323.

6 D. Tang and G. Zhang, Efficient removal of fluoride by hierarchical Ce-Fe bimetal oxides adsorbent: thermodynamics, kinetics and mechanism, Chem. Eng. J., 2016 Jan 1, 283, 721-729.

7 S. Deng, H. Liu, W. Zhou, J. Huang and G. Yu, Mn-Ce oxide as a high-capacity adsorbent for fluoride removal from water, J. Hazard. Mater., 2011 Feb 28, 186(2), 1360-1366.

8 A. Ghosh, S. Chakrabarti, K. Biswas and U. C. Ghosh, Agglomerated nanoparticles of hydrous Ce(Iv) $+\mathrm{Zr}$ (Iv) mixed oxide: Preparation, characterization and physicochemical aspects on fluoride adsorption, Appl. Surf. Sci., 2014 Jul 15, 307, 665-676.

9 L. Chen, K. Zhang, J. He, X. G. Cai, W. Xu and J. H. Liu, Performance and mechanism of hierarchically porous $\mathrm{Ce}-$ Zr oxide nanospheres encapsulated calcium alginate beads for fluoride removal from water, $R S C A d v$., 2016, 6(43), 36296-36306.

10 H. Liu, S. Deng, Z. Li, G. Yu and J. Huang, Preparation of AlCe hybrid adsorbent and its application for defluoridation of drinking water, J. Hazard. Mater., 2010 Jul 15, 179(1), 424430.

11 J. Zhu, X. Lin, P. Wu, Q. Zhou and X. Luo, Fluoride removal from aqueous solution by $\mathrm{Al}(\mathrm{III})-\mathrm{Zr}(\mathrm{Iv})$ binary oxide adsorbent, Appl. Surf. Sci., 2015 Dec 1, 357, 91-100.

12 P. Chen, W. Zhang, M. Li, P. Ai, L. Tian and H. Jiang, Facile synthesis of magnetic La-Zr composite as high effective adsorbent for fluoride removal, RSC Adv., 2016, 6(42), 35859-35867.

13 V. Tomar, S. Prasad and D. Kumar, Adsorptive removal of fluoride from water samples using $\mathrm{Zr}-\mathrm{Mn}$ composite material, Microchem. J., 2013 Jul 31, 111, 116-124.

14 M. Barathi, A. S. Kumar and N. Rajesh, Efficacy of novel Al-Zr impregnated cellulose adsorbent prepared using microwave irradiation for the facile defluoridation of water, J. Environ. Chem. Eng., 2013 Dec 31, 1(4), 1325-1335.
15 Z. Qiusheng, L. Xiaoyan, Q. Jin, W. Jing and L. Xuegang, Porous zirconium alginate beads adsorbent for fluoride adsorption from aqueous solutions, $R S C A d v$., 2015, 5(3), 2100-2112.

16 L. Chen, B. Y. He, S. He, T. J. Wang, C. L. Su and Y. Jin, Fe-Ti oxide nano-adsorbent synthesized by co-precipitation for fluoride removal from drinking water and its adsorption mechanism, Powder Technol., 2012 Sep 30, 227, 3-8.

17 K. Biswas, S. K. Saha and U. C. Ghosh, Adsorption of fluoride from aqueous solution by a synthetic iron(III)-aluminum(III) mixed oxide, Ind. Eng. Chem. Res., 2007 Aug 1, 46(16), 53465356.

18 T. Basu and U. C. Ghosh, Nano-structured iron(III)cerium(Iv) mixed oxide: Synthesis, characterization and arsenic sorption kinetics in the presence of co-existing ions aiming to apply for high arsenic groundwater treatment, Appl. Surf. Sci., 2013 Oct 15, 283, 471-481.

19 L. Chai, Y. Wang, N. Zhao, W. Yang and X. You, Sulfatedoped $\mathrm{Fe}_{3} \mathrm{O}_{4} / \mathrm{Al}_{2} \mathrm{O}_{3}$ nanoparticles as a novel adsorbent for fluoride removal from drinking water, Water Res., $2013 \mathrm{Aug}$ 1, 47(12), 4040-4049.

20 M. Mohapatra, D. Hariprasad, L. Mohapatra, S. Anand and B. K. Mishra, Mg-doped nanoferrihydrite-A new adsorbent for fluoride removal from aqueous solutions, Appl. Surf. Sci., 2012 Mar 1, 258(10), 4228-4236.

21 W. Yang, X. Dou, Y. Li, D. Mohan, C. U. Pittman and Y. S. Ok, Performance and mass transfer of aqueous fluoride removal by a magnetic alumina aerogel, $R S C A d v ., 2016,6(114)$, 112988-112999, used for TG-DTA.

22 S. P. Suriyaraj and R. Selvakumar, Advances in nanomaterial based approaches for enhanced fluoride and nitrate removal from contaminated water, RSC Adv., 2016, 6(13), 1056510583.

23 A. Mohseni-Bandpi, B. Kakavandi, R. R. Kalantary, A. Azari and A. Keramati, Development of a novel magnetitechitosan composite for the removal of fluoride from drinking water: adsorption modeling and optimization, RSC Adv., 2015, 5(89), 73279-73289.

24 K. Pandi and N. Viswanathan, A novel metal coordination enabled in carboxylatedalginic acid for effective fluoride removal, Carbohydr. Polym., 2015 Mar 15, 118, 242-249.

$25 \mathrm{~T}$. Wu, L. Mao and H. Wang, Adsorption of fluoride on $\mathrm{Mg} / \mathrm{Fe}$ layered double hydroxides material prepared via hydrothermal process, RSC Adv., 2015, 5(30), 23246-23254.

26 H. M. Cai, G. J. Chen, C. Y. Peng, Z. Z. Zhang, Y. Y. Dong, G. Z. Shang, X. H. Zhu, H. J. Gao and X. C. Wan, Removal of fluoride from drinking water using tea waste loaded with Al/Fe oxides: A novel, safe and efficient biosorbent, Appl. Surf. Sci., 2015 Feb 15, 328, 34-44.

$27 \mathrm{X}$. Wu, Y. Zhang, X. Dou and M. Yang, Fluoride removal performance of a novel $\mathrm{Fe}-\mathrm{Al}-\mathrm{Cetrimetal}$ oxide adsorbent, Chemosphere, 2007 Nov 30, 69(11), 1758-1764.

28 K. Biswas, K. Gupta, A. Goswami and U. C. Ghosh, Fluoride removal efficiency from aqueous solution by synthetic iron(III)-aluminum(III)-chromium(III) ternary mixed oxide, Desalination, 2010 May 31, 255(1), 44-51. 
29 K. Biswas, D. Bandhoyapadhyay and U. C. Ghosh, Adsorption kinetics of fluoride on iron(III)-zirconium(IV) hybrid oxide, Adsorption, 2007 Feb 1, 13(1), 83-94.

30 S. K. Swain, T. Patnaik, P. C. Patnaik, U. Jha and R. K. Dey, Development of new alginate entrapped Fe(III)-Zr(Iv) binary mixed oxide for removal of fluoride from water bodies, Chem. Eng. J., 2013 Jan 15, 215, 763-771.

31 M. G. Sujana and S. Anand, Iron and aluminium based mixed hydroxides: a novel sorbent for fluoride removal from aqueous solutions, Appl. Surf. Sci., 2010 Sep 15, 256(23), 6956-6962.

32 B. M. Babić, S. K. Milonjić, M. J. Polovina and B. V. Kaludierović, Point of zero charge and intrinsic equilibrium constants of activated carbon cloth, Carbon, 1999 Feb 22, 37(3), 477-481.

33 W. J. Weber and J. C. Morris, Kinetics of adsorption on carbon from solution, Journal of the Sanitary Engineering Division, 1963 Mar, 89(2), 31-60.

34 I. Saha, A. Ghosh, D. Nandi, K. Gupta, D. Chatterjee and U. C. Ghosh, $\beta$-Cyclodextrin modified hydrous zirconium oxide: synthesis, characterization and defluoridation performance from aqueous solution, Chem. Eng. J., 2015 Mar 1, 263, 220-230.
35 I. Langmuir, The constitution and fundamental properties of solids and liquids. Part I. Solids, J. Am. Chem. Soc., 1916 Nov, 38(11), 2221-2295.

36 H. M. Freundlich, Over the adsorption in solution, J. Phys. Chem., 1906 Mar, 57(385471), 1100-1107.

37 O. J. Redlich and D. L. Peterson, A useful adsorption isotherm, J. Phys. Chem., 1959, 63, 1024.

38 A. A. Daifullah, S. M. Yakout and S. A. Elreefy, Adsorption of fluoride in aqueous solutions using KMnO 4-modified activated carbon derived from steam pyrolysis of rice straw, J. Hazard. Mater., 2007 Aug 17, 147(1), 633-643.

39 M. M. Dubinin and L. V. Radushkevich, Equation of the characteristic curve of activated charcoal, Chem. Zentralbl., 1947, 1(1), 875.

40 I. Saha, S. Kanrar, K. Gupta, B. Show, D. Nandi, K. Biswas, B. Manna, D. Chatterjee and U. C. Ghosh, Tuned synthesis and characterizational insight into $\beta$-cyclodextrin amended hydrous iron-zirconium hybrid oxide: a promising scavenger of fluoride in aqueous solution, RSC Adv., 2016, 6(96), 93842-93854.

41 Y. Chen, Q. Zhang, L. Chen, H. Bai and L. Li, Basic aluminumsulfate@ graphene hydrogel composites: preparation and application for removal of fluoride, $J$. Mater. Chem. A, 2013, 1(42), 13101-13110. 